\title{
Solvent Extraction of An(III) and Ln(III) using TODGA in Aromatic Diluents to Suppress Third Phase Formation
}

\author{
Patrik Weßling, ${ }^{*, a, b}$ Udo Müllich, ${ }^{a}$ Elise Guerinoni, ${ }^{\mathrm{c}}$ Andreas Geist, ${ }^{\mathrm{a}}$ and Petra J. Panak ${ }^{\mathrm{a}, \mathrm{b}}$ \\ ${ }^{\text {a }}$ Karlsruhe Institute of Technology (KIT), Institute for Nuclear Waste Disposal (INE), \\ P. O. Box 3640, 76021 Karlsruhe, Germany \\ ${ }^{\mathrm{b}}$ Ruprecht-Karls-Universität Heidelberg, Institut für Physikalische Chemie, \\ Im Neuenheimer Feld 253, 69120 Heidelberg, Germany \\ ${ }^{\mathrm{c}}$ École Nationale Supérieure de Chimie de Montpellier, France
}

\begin{abstract}
The extraction of nitric acid, trivalent actinides and lanthanides with $N, N, N$ ', $N$ '-tetra- $n$-octyl3-oxapentanediamide (TODGA) dissolved in the aromatic diluents 1,4-diisopropylbenezene and tert-butylbenzene was studied. Nitric acid extraction proceeds along the formation of 1:1 and 2:1 $\mathrm{HNO}_{3}$-TODGA adducts. An(III) and $\mathrm{Ln}$ (III) distribution ratios were determined as a function of nitric acid, TODGA and $\mathrm{Ln}(\mathrm{III})$ concentrations. Distribution ratios are approximately an order of magnitude lower in aromatic diluents compared to aliphatic diluents. No third phase formation was observed when contacting the solvent with an aqueous phase containing $1.5 \mathrm{~mol} / \mathrm{L} \mathrm{Er}\left(\mathrm{NO}_{3}\right)_{3}$ in $2-4.3 \mathrm{~mol} / \mathrm{L} \mathrm{HNO}_{3}$. Slope analysis indicates the formation of 1:3 and 1:4 M(III):TODGA complexes. Using TRLFS, the formation of a previously unknown 1:2 complex in organic phases loaded with $\operatorname{Ln}(\mathrm{III})$ was observed for the first time.
\end{abstract}

\section{KEYWORDS}

TODGA, aromatic diluent, actinides, lanthanides, extraction, spectroscopy

\section{INTRODUCTION}

Lipophilic $N, N, N^{\prime}, N^{\prime}$-tetraalkyl-3-oxapentanediamides (a.k.a. diglycolamides, DGA) have been introduced as extracting agents for various di- and trivalent metal ions. ${ }^{1}$ Later DGA were proposed to efficiently extract actinide and lanthanide ions from nitric acid solutions in the context of radionuclide separations and actinide recycling strategies. ${ }^{2-8}$ Hydrophilic DGA ${ }^{9-10}$ are used as masking agents (holding back metal ions in the aqueous phase during extraction) and stripping agents (back extracting metal ions from a loaded organic phase). ${ }^{11-14}$ Countercurrent process tests using DGA extracting agents $\left(N, N, N^{\prime}, N^{\prime}\right.$-tetra- $n$-octyl-3- 
oxapentanediamide (TODGA, Figure 1) or $\quad N, N, N^{\prime}, N^{\prime}$-tetra-(2-ethylhexyl)-3oxapentanediamide, TEHDGA) have successfully been performed in laboratory scale equipment. ${ }^{15-21}$ TODGA has extensively been used in recent European research programmes on innovative nuclear fuel cycles ${ }^{22-24}$ to develop processes co-extracting actinides and lanthanides followed by selective stripping of actinides. ${ }^{7,17,19,25-30}$

An important issue with DGA extracting agents when dissolved in aliphatic diluents is their proneness to third phase formation when in contact with solutions containing nitric acid and metal ions in elevated concentrations. Third phase formation is suppressed by adding modifiers such as tri- $n$-butyl phosphate (TBP), lipophilic alcohols or monoamides, see the reviews ${ }^{5,8}$ and references therein. Alternatively, using 1-octanol as diluent was proposed. ${ }^{31}$ To allow for the extraction of $\mathrm{Pu}(\mathrm{IV})$ in concentrations of tens of $\mathrm{g} / \mathrm{L}$ by TODGA, $N, N$ '-dimethyl- $N, N^{\prime}$-dioctyl2-[2-(hexyloxy)ethyl]-malonamide ${ }^{32-33}$ (DMDOHEMA, Figure 1) was added as a modifier. ${ }^{34}$
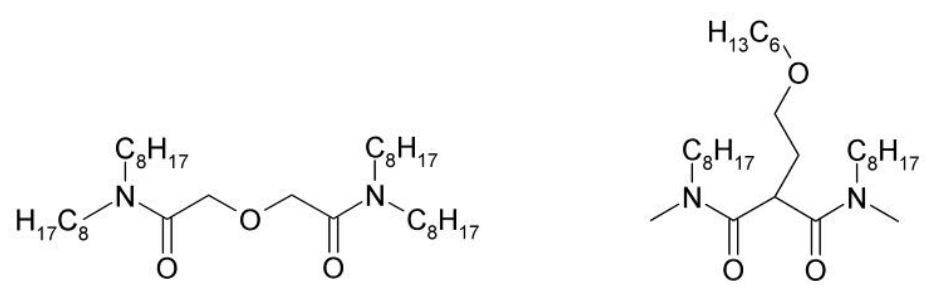

Figure 1. Molecular structures of TODGA and DMDOHEMA.

This however comes with some drawbacks. Using a pure 1-octanol diluent results in significant co-extraction of nitric acid by the diluent, ${ }^{35}$ in addition to the nitric acid extracted by the DGA. 36-38 Adding a modifier may complicate solvent clean-up due to the increased number of constituents each forming various degradation products due to hydrolysis and radiolysis. Finally, modifiers such as TBP, monoamides or DMDOHEMA are extracting agents themselves, resulting in the undesired co-extraction of some solutes such as $\mathrm{Zr}(\mathrm{IV})$ and $\mathrm{Mo}(\mathrm{VI})$ in the case of DMDOHEMA. ${ }^{39}$ Consequently, a solvent would ideally comprise one extractant and one diluent while maintaining high loading capacity without third phase formation.

The loading capacity of the solvent is increased by using a TODGA concentration greater than $0.2 \mathrm{~mol} / \mathrm{L}$. This results in increased distribution ratios of all metal ions (including those to be rejected) and complicates back extraction. To counteract, DGA extracting agents bearing one or two methyl moieties (Figure 2) were developed, showing much lower distribution ratios. ${ }^{39-}$ 41 
<smiles>[R]N([R])C(=O)COC(C)C(=O)N([R])[R]</smiles><smiles>[R]N([R])C(=O)C(C)OC(C)C(=O)N([R])[R]</smiles>

Figure 2. Molecular structures of Me-DGA and diMe-DGA.

Alternatively, a diluent causing smaller distribution ratios compared to aliphatic diluents can be used to counteract the effects of higher extractant concentrations. Aromatic diluents in some cases result in lower distribution ratios compared to aliphatic diluents. ${ }^{42-43}$ As an additional benefit, they protect the extracting agent from radiolytic degradation and they themselves are stable against radiolysis. However, aromatic diluents can be prone to nitration from the nitric acid itself or the $\mathrm{NO}_{3} \cdot$ radical formed by radiolysis of the aqueous phase. ${ }^{44-45}$ As this may affect solvent properties such as extraction performance, selectivity and viscosity, detailed studies on radiolysis and nitration are mandatory. Indeed, toluene had been employed as diluent in early studies on DGA. ${ }^{1-2,46-47}$ Comparing several diluents for DGA, toluene yielded Am(III) and $\mathrm{Eu}(\mathrm{III})$ distribution ratios lower by approximately two orders of magnitude compared to $n$-hexane or $n$-dodecane. ${ }^{3}$

This prompted us to study aromatic compounds as diluents for TODGA in more detail. Following initial successful tests with tert.-butyl benzene (tBuB), more detailed studies using 1,4-diisopropyl benzene (DIPB) followed. Indeed, DIPB had been used in the original version of the TALSPEAK process. ${ }^{48-49} \mathrm{tBuB}$ was used as diluent in the $\mathrm{ALINA}^{50}$ and $\mathrm{LUCA}^{51}$ processes.

This paper presents a comprehensive study on solvents comprising TODGA in aromatic diluents, DIPB and tBuB. Such solvents are a promising alternative to solvents used in actinide separation processes developed in Europe, such as i-SANEX, ${ }^{17,25,28-29} \mathrm{AmSel}^{27}{ }^{27}$ Euro-EXAm ${ }^{14}$ and Euro-GANEX, ${ }^{7,19}$ due to their simple one extractant, one diluent composition. The extraction of nitric acid, trivalent actinides, An(III) and lanthanides, Ln(III) into TODGA dissolved in aromatic diluents (DIPB, tBuB) was determined as a function of shaking time, nitric acid concentration, ligand concentration, metal ion (La(III)) concentration and temperature. Time-resolved laser fluorescence spectroscopy (TRLFS) was employed to confirm the 1:3 stoichiometry of the extracted $\mathrm{Cm}(\mathrm{III})$ and $\mathrm{Eu}(\mathrm{III})$ complexes. Furthermore, the presence of the so far unknown 1:2 Eu(III)-TODGA complex was confirmed in organic phases loaded with $\operatorname{Ln}(\mathrm{III})$. 


\section{EXPERIMENTAL}

\section{Chemicals}

All commercially available chemicals (Alfa Aesar or Sigma-Aldrich) used in this study were analytical reagent grade and used without further purification. TODGA was synthesized as described in the literature. ${ }^{2,4}$ The purity (> $99 \%$ ) was checked using NMR.

\section{Nitric acid extraction}

Each $500 \mu \mathrm{L}$ of $0.3-6.9 \mathrm{~mol} / \mathrm{L} \mathrm{HNO}_{3}$ were contacted with each $500 \mu \mathrm{L}$ of $0.15-0.5 \mathrm{~mol} / \mathrm{L}$ TODGA dissolved in DIPB or with the diluent itself on an orbital shaker $(2500 \mathrm{rpm})$ for $30 \mathrm{~min}$ at $20^{\circ} \mathrm{C}$. After centrifugation ( $2 \mathrm{~min}$ at $6000 \mathrm{rpm}$ ) and phase separation organic phases were stripped into water $(A / O=1-4)$. Initial, aqueous equilibrium and organic equilibrium nitric acid concentrations were determined by potentiometric titration with $0.02 \mathrm{~mol} / \mathrm{L}$ or $0.1 \mathrm{~mol} / \mathrm{L}$ $\mathrm{NaOH}$. A Metrohm titroprocessor equipped with a $1 \mathrm{~mL}$ syringe was used. Titrations were performed in duplicate. Mass balances were 100-104\%.

\section{An(III) and Ln(III) extraction}

Aqueous phases were either $1-20 \mathrm{kBq} / \mathrm{mL}^{241} \mathrm{Am}(\mathrm{III})$ in $0.2-4.9 \mathrm{~mol} / \mathrm{L} \mathrm{HNO}_{3}$ or each $1 \mathrm{kBq} / \mathrm{mL}^{241} \mathrm{Am}$ (III), ${ }^{244} \mathrm{Cm}$ (III) ${ }^{154} \mathrm{Eu}(\mathrm{III})$ and each $12 \mathrm{mg} / \mathrm{L} \mathrm{Y}(\mathrm{III}), \mathrm{La}(\mathrm{III})$ - Lu(III) (except $\mathrm{Pm}(\mathrm{III})$ ) as nitrate salts in $0.045-1.9 \mathrm{~mol} / \mathrm{L} \mathrm{HNO}_{3}$. Organic phases were $0.07-0.5 \mathrm{~mol} / \mathrm{L}$ TODGA in DIPB or tBuB.

Each $500 \mu \mathrm{L}$ of organic and aqueous phases were contacted in $2 \mathrm{~mL}$ screw cap glass vials and shaken for $30 \mathrm{~min}$ (except in case of kinetic experiments) on an orbital vortex shaker at $2500 \mathrm{rpm}$ and $20^{\circ} \mathrm{C}$. This time was sufficient to attain chemical equilibrium (cf. SI, Figure S1). Phases were centrifuged for $2 \mathrm{~min}$ at $6000 \mathrm{rpm}$ and $300 \mu \mathrm{L}$ aliquots were separated.

Gamma counting for ${ }^{241} \mathrm{Am}$ (III) and ${ }^{154} \mathrm{Eu}(\mathrm{III})$ was performed on a Packard Cobra Auto-Gamma 5003. For $\alpha$ spectrometry of ${ }^{241} \mathrm{Am}$ (III) and ${ }^{244} \mathrm{Cm}$ (III), organic phases were stripped into $0.5 \mathrm{~mol} / \mathrm{L}$ ammonium glycolate solution $(\mathrm{pH}=4, A / O=10)$. Aqueous phases were diluted with the same solution. For determination of Y(III) and $\operatorname{Ln}($ III) by ICP-MS, aliquots of the samples prepared for $\alpha$ spectrometry were further diluted with $2 \%$ ultrapure $\mathrm{HNO}_{3}$. 


\section{Kinetic experiments}

Preliminary kinetic experiments were performed to determine the time required to attain equilibrium. Aqueous phase was $1 \mathrm{~mol} / \mathrm{L} \mathrm{HNO}_{3}$, organic phase was $0.2 \mathrm{~mol} / \mathrm{L}$ TODGA in DIPB. Samples were shaken for 2, 5, 10, 20, 30 or $60 \mathrm{~min}$.

\section{Temperature dependent extraction}

Aqueous phases were $1 \mathrm{~mol} / \mathrm{L} \mathrm{HNO}_{3}$. Organic phases were $0.2 \mathrm{~mol} / \mathrm{L}$ TODGA in DIPB. Equal amounts of aqueous and organic phase were shaken and centrifuged at $10,20,30,40$ and $50^{\circ} \mathrm{C}$.

\section{Ln(III) loading}

Aqueous solutions containing $1.5 \mathrm{~mol} / \mathrm{L} \mathrm{Er}\left(\mathrm{NO}_{3}\right)_{3}$ in $2-4.3 \mathrm{~mol} / \mathrm{L} \mathrm{HNO}_{3}$ were contacted with organic phases containing $0.1-0.5 \mathrm{~mol} / \mathrm{L}$ TODGA in DIPB ( $t=30 \mathrm{~min}, T=293 \mathrm{~K}, A / O=1)$, centrifuged and visually inspected for third phase formation.

A $\mathrm{La}(\mathrm{III})$ loading isotherm was established extracting $\mathrm{La}\left(\mathrm{NO}_{3}\right)_{3}(0.01-1.84 \mathrm{~mol} / \mathrm{L})$ from $1 \mathrm{~mol} / \mathrm{L} \mathrm{HNO}_{3}$ into $0.1 \mathrm{~mol} / \mathrm{L}$ TODGA dissolved in DIPB. Organic phases were stripped into ammonium glycolate solution $(A / O=10)$. La concentrations in organic and aqueous phases were analysed by ICP-MS following dilution.

\section{TRLFS sample preparation}

Organic phases for $\mathrm{Cm}$ (III) TRLFS were prepared by extracting $10^{-7} \mathrm{~mol} / \mathrm{L} \mathrm{Cm}$ (III) from $0.3 \mathrm{~mol} / \mathrm{L}, 1 \mathrm{~mol} / \mathrm{L}$ or $5 \mathrm{~mol} / \mathrm{L} \mathrm{HNO}_{3}$ into $0.2 \mathrm{~mol} / \mathrm{L}$ TODGA dissolved in DIPB. Ln(III)-loaded organic phases for $\mathrm{Eu}(\mathrm{III})$ TRLFS measurements were prepared by extracting $1.84 \mathrm{~mol} / \mathrm{L}$ $\mathrm{M}\left(\mathrm{NO}_{3}\right)_{3}(\mathrm{M}=\mathrm{Y}, \mathrm{La}, \mathrm{Nd}, \mathrm{Sm}, \mathrm{Gd}, \mathrm{Eu}, \mathrm{Er})$ solutions in $1 \mathrm{~mol} / \mathrm{L} \mathrm{HNO}_{3}$ spiked with $10^{-4} \mathrm{~mol} / \mathrm{L}$ or $10^{-5} \mathrm{~mol} / \mathrm{L} \mathrm{Eu}\left(\mathrm{NO}_{3}\right)_{3}$ (no spike in case of $1.84 \mathrm{~mol} / \mathrm{L} \mathrm{Eu}\left(\mathrm{NO}_{3}\right)_{3}$ ) into $0.1 \mathrm{~mol} / \mathrm{L}$ TODGA dissolved in DIPB or TPH +5 vol. $\%$ 1-octanol. After centrifugation $300 \mu \mathrm{L}$ aliquots of the loaded organic phases were transferred into quartz cuvettes and analysed by TRLFS.

\section{TRLFS measurements}

TRLFS measurements were performed at $298 \mathrm{~K}$ using a Nd:YAG (Surelite II laser, Continuum) pumped dye laser system (NarrowScan D-R; Radiant Dyes Laser Accessories GmbH). A wavelength of $396.6 \mathrm{~nm}$ and $394 \mathrm{~nm}$ was chosen to excite $\mathrm{Cm}(\mathrm{III})$ and $\mathrm{Eu}(\mathrm{III})$, respectively. A spectrograph (Shamrock 303i, ANDOR) with 300, 1199 and 2400 lines per mm gratings was used for spectral decomposition. The fluorescence emission was detected by an ICCD camera 
(iStar Gen III, ANDOR) after a delay time of $1 \mu \mathrm{s}$ to discriminate short-lived organic fluorescence and light scattering.

\section{RESULTS AND DISCUSSION}

\section{Nitric acid extraction with TODGA in DIPB}

The extraction of nitric acid by TODGA dissoveld in DIPB was determined at TODGA concentrations in the range of $0.15-0.5 \mathrm{~mol} / \mathrm{L}$. The extraction of nitric acid by the diluent DIPB itself was also determined. No third phase formation was observed within the range of the initial nitric acid concentrations investigated $(0.3-6.9 \mathrm{~mol} / \mathrm{L})$. Organic equilibrium nitric acid concentrations as a function of initial aqueous nitric acid concentration are shown in Figure 3, together with calculated values (see below).

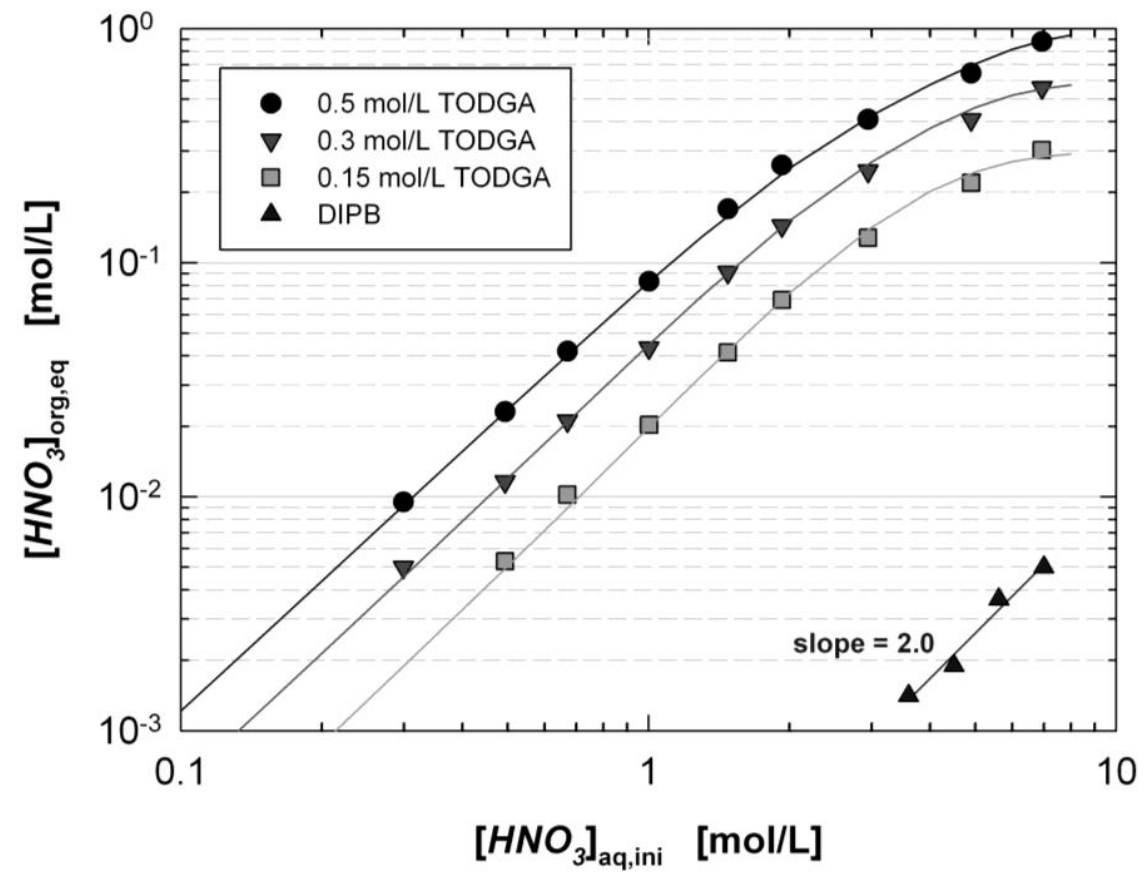

Figure 3. Organic equilibrium nitric acid concentration as a function of initial aqueous nitric acid concentration for the extraction with TODGA in DIPB and DIPB itself. $A / O=1 ; t=30 \mathrm{~min} ; T=20^{\circ} \mathrm{C}$. Symbols, experiments. Lines, calculated (except "slope" line).

Compared to aliphatic alcohols or mixtures of aliphatic alcohols and kerosene, ${ }^{35}$ DIPB itself extracts only small concentrations of nitric acid. The concentrations are negligible compared to the total nitric acid extraction by TODGA and DIPB, see Figure 3. According to the following equation 


$$
\left[\mathrm{H}^{+}\right]_{a q}+\left[\mathrm{NO}_{3}^{-}\right]_{a q} \rightleftharpoons\left[\mathrm{HNO}_{3}\right]_{\text {org }}
$$

a slope of two confirms that nitric acid is present in the organic phase as an undissociated molecule.

Detectable nitric acid extraction by TODGA starts at an initial nitric acid concentration of $0.3 \mathrm{~mol} / \mathrm{L}$ albeit in small concentrations $\left(\left[\mathrm{HNO}_{3}\right]_{\text {org, eq }}<0.01 \mathrm{~mol} / \mathrm{L}\right)$. A monotonic increase of the organic equilibrium nitric acid concentration with increasing initial nitric acid concentration is observed. This increase, however, gets less pronounced for initial nitric acid concentrations greater than $2 \mathrm{~mol} / \mathrm{L}$, indicating the beginning of the saturation of the organic phase.

Nitric acid extraction by a $0.3 \mathrm{~mol} / \mathrm{L}$ TODGA-DIPB solvent is approximately $55 \%$ (at initial aqueous nitric acid concentrations up to $0.5 \mathrm{~mol} / \mathrm{L}$ ) and approximately $80 \%$ (beyond $2 \mathrm{~mol} / \mathrm{L}$ ), respectively, of the concentrations extracted by a $0.3 \mathrm{~mol} / \mathrm{L}$ TODGA-TPH/1-octanol solvent. ${ }^{6}$ Consequently, using the aromatic diluent will have an effect on a process flow-sheet as less extracted nitric acid will be routed to the scrubbing and back-extraction stages.

The extraction of nitric acid by TODGA and similar DGA extracting agents is reported to proceed along the formation of the (TODGA) $\left(\mathrm{HNO}_{3}\right)$ adduct at low and intermediate nitric acid concentrations and (TODGA) $\left(\mathrm{HNO}_{3}\right)_{2}$ at elevated nitric acid concentrations. ${ }^{38}$ The presence of the latter adduct is evident for aqueous nitric acid concentrations greater than $3 \mathrm{~mol} / \mathrm{L}$, where the nitric acid concentration in the organic phase exceeds the TODGA concentration, see Figure 3.

The modelling approach described in reference ${ }^{33}$ was followed to calculate nitric acid extraction as a function of initial nitrc acid and TODGA concentrations. Accounting for the (TODGA) $\left(\mathrm{HNO}_{3}\right)$ and $(\mathrm{TODGA}) \cdot\left(\mathrm{HNO}_{3}\right)_{2}$ adducts, with a conditional extraction constant for the $1: 1$ adduct,

$$
\begin{aligned}
K_{\mathrm{H} 11} & =\frac{\left[\left(\mathrm{HNO}_{3}\right) L\right]}{\left(\mathrm{H}^{+}\right) \cdot\left(\mathrm{NO}_{3}^{-}\right) \cdot[L]}=0.32+\left([L]_{t o t}-0.3\right) * 0.4 \\
K_{\mathrm{H} 21} & =\frac{\left[\left(\mathrm{HNO}_{3}\right)_{2} L\right]}{\left(\mathrm{H}^{+}\right)^{2} \cdot\left(\mathrm{NO}_{3}^{-}\right)^{2} \cdot[\mathrm{L}]}=0.01
\end{aligned}
$$

The model uses activities in the aqueous phase calculated by the Specific Ion Interaction Theory (SIT), see references. ${ }^{52-53}$ Concentrations rather than activities are used in the organic phase. The minute extraction of nitric acid by DIPB is neglected.

This model accurately calculates nitric acid extraction, see Figure 3. Additonally considering the $(\mathrm{TODGA})_{2} \cdot\left(\mathrm{HNO}_{3}\right)$ adduct allowed for using non-conditional extraction constants for all three adducts but resulted in considerable deviations for initial nitric acid concentrations in the 
range of 1-3 mol/L. Certainly, a more sophisticated model (see e. g. reference ${ }^{6}$ ) might yield better agreement with the experimental data. However, the rather limited set of data available does not warrant such a procedure.

\section{Extraction of Am(III) as a function of nitric acid and TODGA concentrations}

The extraction of Am(III) was studied over a range of nitric acid (0.2-4.9 mol/L) and TODGA $(0.05-0.5 \mathrm{~mol} / \mathrm{L})$ concentrations. Distribution ratios for Am(III) as a function of the initial nitric acid and TODGA concentrations are shown in Figure 4 and Figure 5, respectively.

Am(III) distribution ratios increase with increasing nitric acid (and thus nitrate) concentration, in accordance with extraction by solvation,

$$
\mathrm{Am}^{3+}+3 \mathrm{NO}_{3}{ }^{-}+n \text { TODGA } \rightleftharpoons \mathrm{Am}\left(\mathrm{NO}_{3}\right)_{3}(\mathrm{TODGA})_{n}
$$

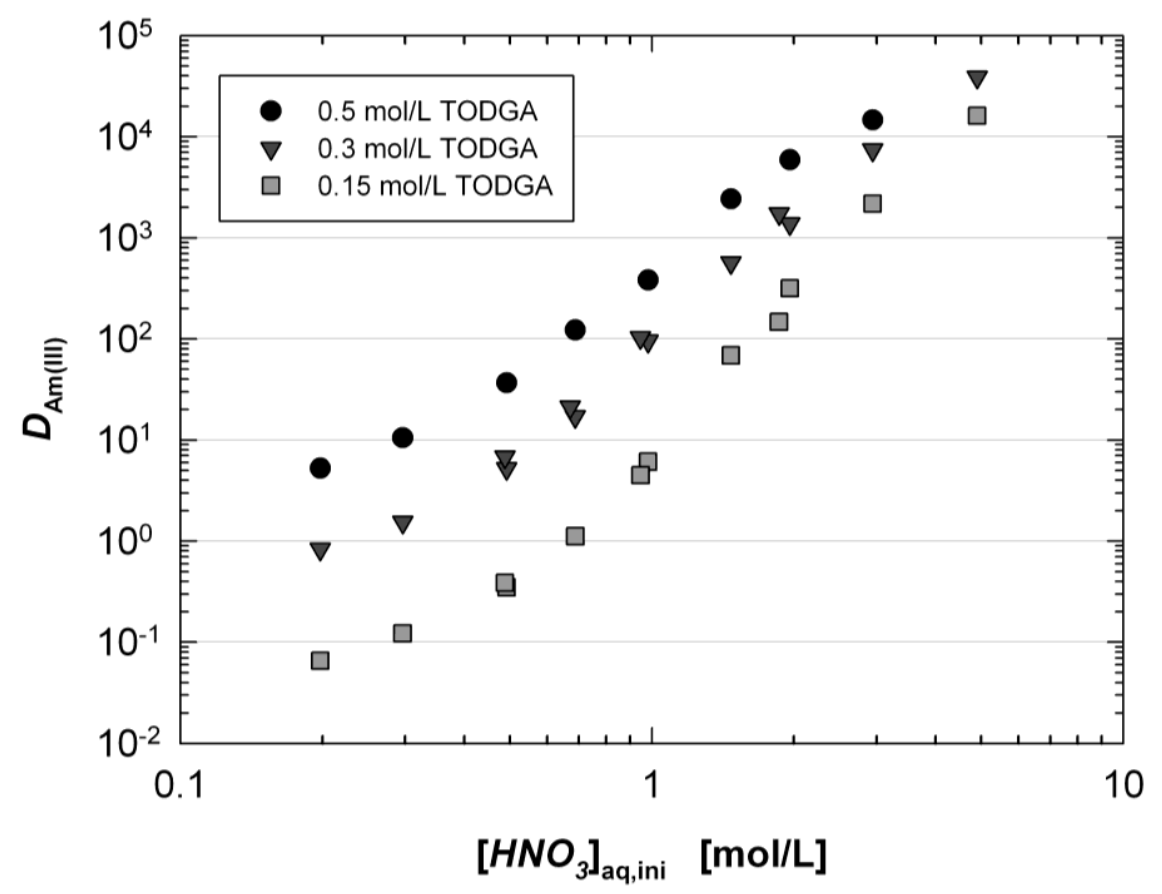

Figure 4. Am(III) distribution ratios for the extraction with TODGA in DIPB as a function of the initial nitric acid concentration. $A / O=1 ; t=30 \mathrm{~min} ; T=20^{\circ} \mathrm{C}$.

Slope analysis was performed to determine the number of TODGA molecules in the extracted Am(III) complexes. Am(III) distribution ratios (Figure 4) were re-plotted as a function of the equilibrium nitric concentration and plotted as a function of the equilibrium TODGA 
concentration (calculated using the equilibrium model for nitric acid concentration), see Figure 5. For more details on the procedure, see reference. ${ }^{33}$

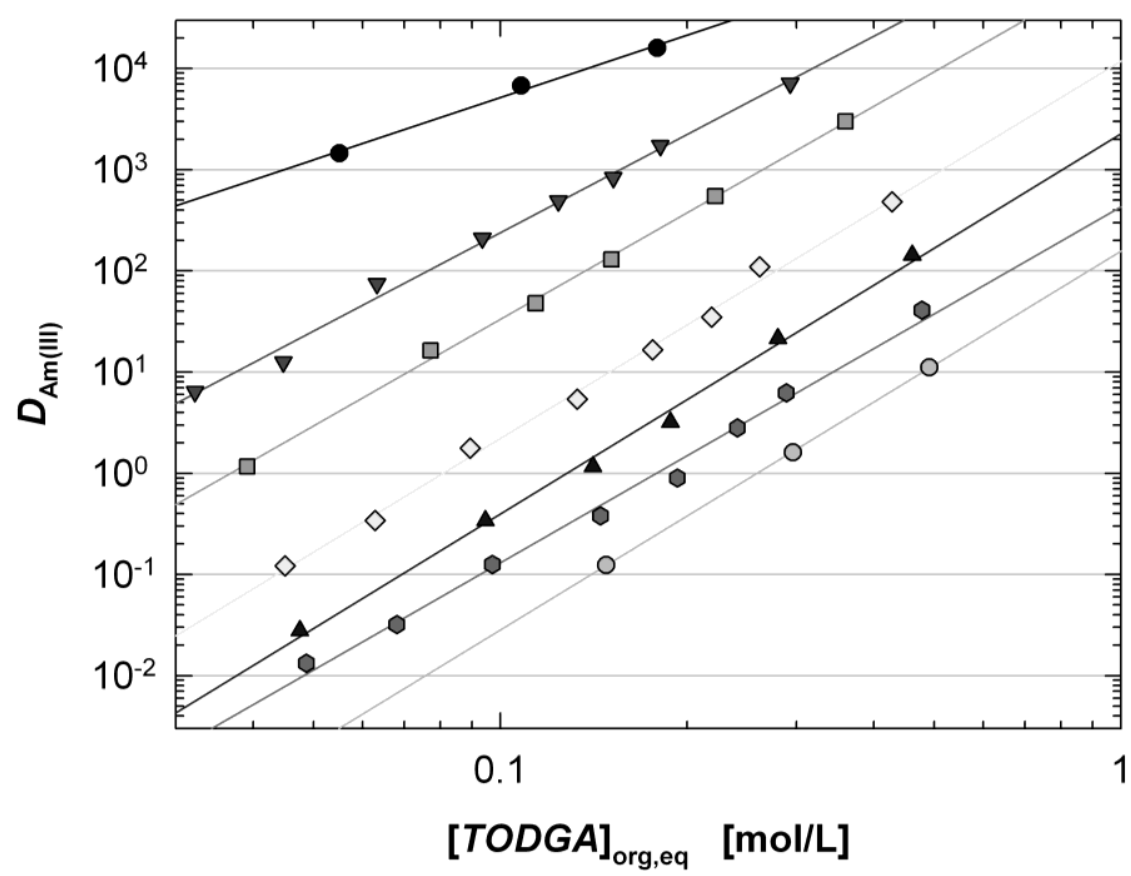

slope $=2.1$ $2.55 \mathrm{~mol} / \mathrm{L} \mathrm{HNO}_{3}$

$\nabla \quad$ slope $=3.2$ $1.79 \mathrm{~mol} / \mathrm{L} \mathrm{HNO}_{3}$

․ $\quad$ slope $=3.5$ $1.38 \mathrm{~mol} / \mathrm{L} \mathrm{HNO}_{3}$

$\diamond \quad$ slope $=3.7$ $0.93 \mathrm{~mol} / \mathrm{L} \mathrm{HNO}_{3}$

$\Delta \quad$ slope $=3.8$ $0.66 \mathrm{~mol} / \mathrm{L} \mathrm{HNO}_{3}$

- $\quad$ slope $=3.5$ $0.48 \mathrm{~mol} / \mathrm{L} \mathrm{HNO}_{3}$

O $\quad$ slope $=3.7$ $0.29 \mathrm{~mol} / \mathrm{L} \mathrm{HNO}_{3}$

Figure 5. Am(III) distribution ratios for the extraction with TODGA in DIPB as a function of the TODGA concentration. Equilibrium $\mathrm{HNO}_{3}$ concentrations and slopes as indicated in legend. $A / O=1 ; t=30 \mathrm{~min} ; T=$ $20^{\circ} \mathrm{C}$.

For equilibrium nitric acid concentrations up to $1.4 \mathrm{~mol} / \mathrm{L}$, the slopes are in the range of $3.5-$ 3.8, indicating the extraction of $\mathrm{Am}$ (III) as a 1:4 complex. For a nitric acid concentration of $1.8 \mathrm{~mol} / \mathrm{L}$ the slope is close to 3 , indicating the extraction of $\mathrm{Am}(\mathrm{III})$ as a 1:3 complex. Finally, the slope of 2.1 observed at $2.6 \mathrm{~mol} / \mathrm{L}$ nitric acid may be interpreted as evidence for a $1: 2$ complex, However, the presumably greater uncertainties for the very high distribution ratios and the low number of data points does not allow for strong conclusions.

On one hand, literature reports the extraction of $\mathrm{An}(\mathrm{III})$ and $\mathrm{Ln}(\mathrm{III})$ to proceed along the formation of $1: 2,1: 3$ or 1:4 complexes depending on experimental conditions, see ${ }^{5,8}$ and references therein. On the other hand, spectroscopic investigations ${ }^{54-56}$ by TRLFS of Cm(III) and $\mathrm{Eu}(\mathrm{III})$ extracted with DGA dissolved in kerosene clearly show the inner coordination sphere to contain three DGA molecules and no water or nitrate molecules, i. e. they are extracted as $\left[\mathrm{M}(\mathrm{DGA})_{3}\right]^{3+}$ complexes with outer-sphere nitrate anions to compensate the charge.

Consequently, $\mathrm{Cm}$ (III) and $\mathrm{Eu}(\mathrm{III})$ extracted from $0.3-5 \mathrm{~mol} / \mathrm{L}$ nitric acid by TODGA dissolved in DIPB or $\mathrm{tBuB}$ were studied by TRLFS. The respective $\mathrm{Cm}$ (III) and $\mathrm{Eu}(\mathrm{III})$ fluorescence spectra are shown in the SI, Figure S2. They are in excellent agreement with spectra of the 
$\mathrm{Cm}(\mathrm{III})$ and $\mathrm{Eu}(\mathrm{III})$ 1:3 DGA complexes found in monophasic titration experiments ${ }^{14,54}$ and extraction experiments using aliphatic diluents. ${ }^{54-56}$ In conclusion, the same $\left[\mathrm{M}(\mathrm{DGA})_{3}\right]^{3+}$ complexes are formed during the extraction into the aromatic diluents DIPB and tBuB. Fluorescence lifetimes of the extracted $\mathrm{Cm}$ (III) and $\mathrm{Eu}(\mathrm{III})$ complexes are in the range of 455$508 \mu \mathrm{s}(\mathrm{Cm}(\mathrm{III}))$ and $1855-2100 \mu \mathrm{s}(\mathrm{Eu}(\mathrm{III}))$. According to the correlations of lifetime and number of coordinating water molecules, ${ }^{57-58}$ these results confirm the absence of water molecules in the inner coordination sphere (cf. SI, Figure S3).

The spectroscopic results do not necessarily contradict extraction in the form of 1:4 complexes. This technique probes the inner coordination sphere of the extracted metal ion, showing it to be directly coordinated to three TODGA molecules regardless of the nitric acid concentration. Additional TODGA molecules associated in the outer sphere will remain undetected.

\section{Extraction An(III) and Ln(III) with TODGA dissolved in aromatic diluents}

The extraction of An(III) and Ln(III) with $0.2 \mathrm{~mol} / \mathrm{L}$ TODGA dissolved in DIPB or tBuB was studied as a function of the initial nitric acid concentration. Distribution ratios for Am(III), $\mathrm{Cm}(\mathrm{III}), \mathrm{Y}(\mathrm{III})$ and the lighter Ln(III) are shown in Figure 6 for the TODGA-DIPB solvent. Distribution data for the heavier Ln(III) into the TODGA-DIPB solvent and further distribution data for the TODGA-tBuB solvent are shown in the SI, Figures S3 A-C. 


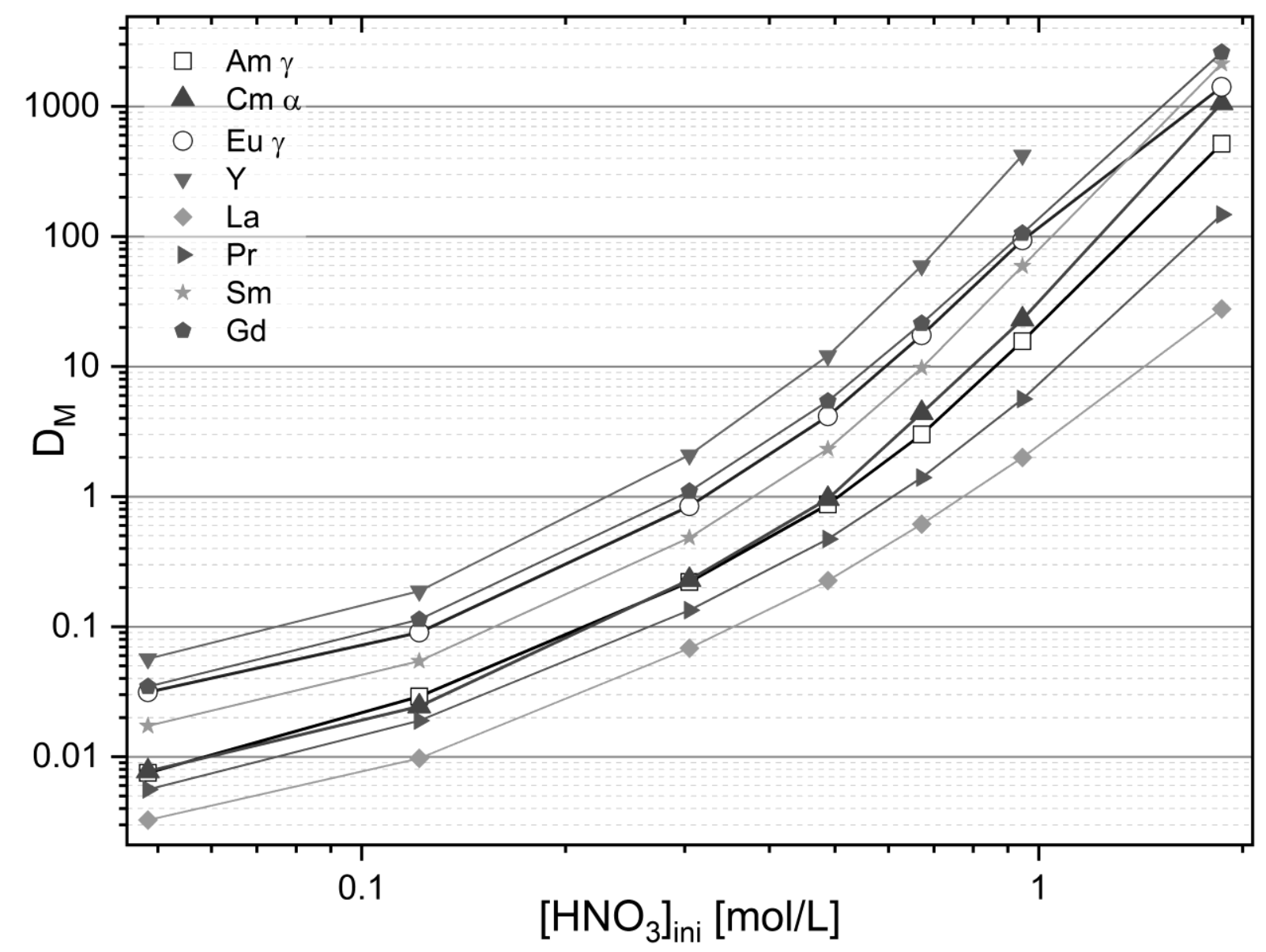

Figure 6. Distribution ratios for the extraction of ${ }^{241} \mathrm{Am}(\mathrm{III}),{ }^{244} \mathrm{Cm}(\mathrm{III}),{ }^{154} \mathrm{Eu}(\mathrm{III}), \mathrm{Y}(\mathrm{III}), \mathrm{La}(\mathrm{III}), \mathrm{Pr}(\mathrm{III})$, $\mathrm{Sm}(\mathrm{III})$ and $\mathrm{Gd}(\mathrm{III})$ with $0.2 \mathrm{~mol} / \mathrm{L}$ TODGA in DIPB as a function of the initial nitric acid concentration. $A / O=1 ; t=30 \min ; T=20^{\circ} \mathrm{C}$.

Both systems (TODGA in DIPB and TODGA in tBuB) behave similarly. Extraction $\left(D_{\mathrm{M}(\mathrm{III})}>1\right)$ of $\mathrm{Am}(\mathrm{III})$ and $\mathrm{Cm}(\mathrm{III})$ is observed for nitric acid concentrations greater than $0.5 \mathrm{~mol} / \mathrm{L}$. $\mathrm{Ln}(\mathrm{III})$ extraction starts at nitric acid concentrations between $0.15 \mathrm{~mol} / \mathrm{L}$ and $0.8 \mathrm{~mol} / \mathrm{L}$, depending on the $\mathrm{Ln}(\mathrm{III})$. For nitric acid concentrations greater than $2 \mathrm{~mol} / \mathrm{L}$ distribution ratios for most of the metal ions are too high $\left(D_{\mathrm{M}(\mathrm{III})}>5000\right)$ to be determined accurately.

As observed earlier, ${ }^{3,25,59}$ heavier Ln(III) are better extracted than the lighter ones. Am(III) and $\mathrm{Cm}$ (III) show distribution ratios similar to those of $\mathrm{Nd}(\mathrm{III})$. In general, intra-Ln(III) selectivity (at $0.5 \mathrm{~mol} / \mathrm{L} \mathrm{HNO}_{3}$ ) is slightly lower in DIPB and tBuB compared to aliphatic diluents, Figure 7 and Figure S5.

Figure 7 compares $\mathrm{An}(\mathrm{III})$ and $\mathrm{Ln}(\mathrm{III})$ distribution ratios for TODGA in DIPB, tBuB and TPH/1-octanol at comparable experimental conditions $\left(0.5 \mathrm{~mol} / \mathrm{L} \mathrm{HNO}_{3}\right.$ and $0.2 \mathrm{~mol} / \mathrm{L}$ TODGA). Distribution ratios are approximately two orders of magnitude lower for the aromatic diluents compared to TPH/1-octanol, ${ }^{25}$ in agreement with earlier observations. ${ }^{3}$ 


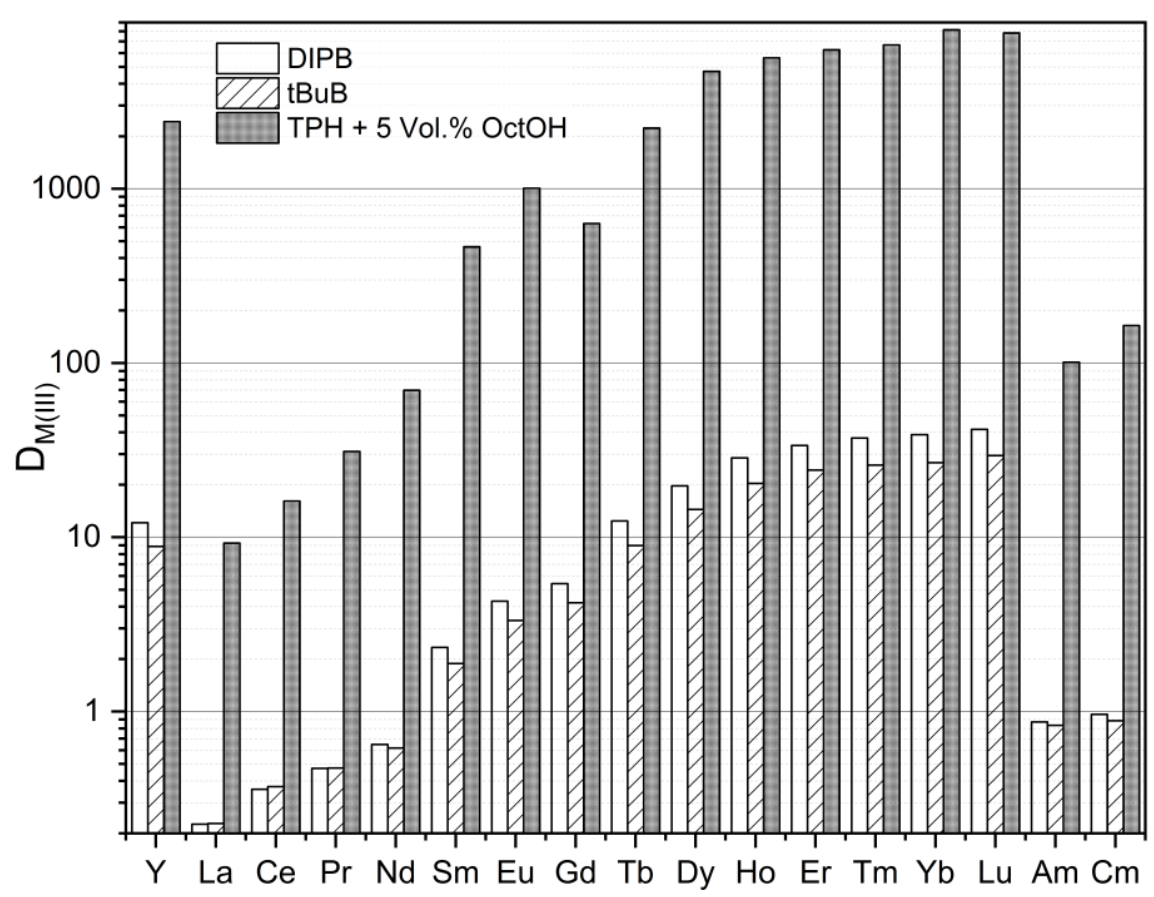

Figure 7. Comparison of $\mathrm{Am}(\mathrm{III}), \mathrm{Cm}(\mathrm{III}), \mathrm{Y}(\mathrm{III})$ and $\mathrm{Ln}(\mathrm{III})$ distribution ratios for the extraction from $0.5 \mathrm{~mol} / \mathrm{L} \mathrm{HNO}_{3}$ into $0.2 \mathrm{~mol} / \mathrm{L}$ TODGA dissolved in aromatic diluents (DIPB, tBuB) and an aliphatic diluent (TPH with 5 vol.\% 1-octanol; data from reference ${ }^{25}$ ).

Due to the small differences between the two aromatic solvents, all further experiments were performed with DIPB only.

\section{Temperature dependent Am(III) and Ln(III) distribution data}

Am(III) and $\operatorname{Ln}(\mathrm{III})$ distribution were determined at varied temperature $\left(10-50^{\circ} \mathrm{C}\right)$. Figure 8 shows distribution ratios for $\mathrm{Am}(\mathrm{III}), \mathrm{Y}(\mathrm{III})$ and $\mathrm{La}(\mathrm{III})$ - Gd(III) as a function of the temperature. Distribution ratios for the heavier $\operatorname{Ln}(\mathrm{III})$ are reported in the SI, Figure S6. 


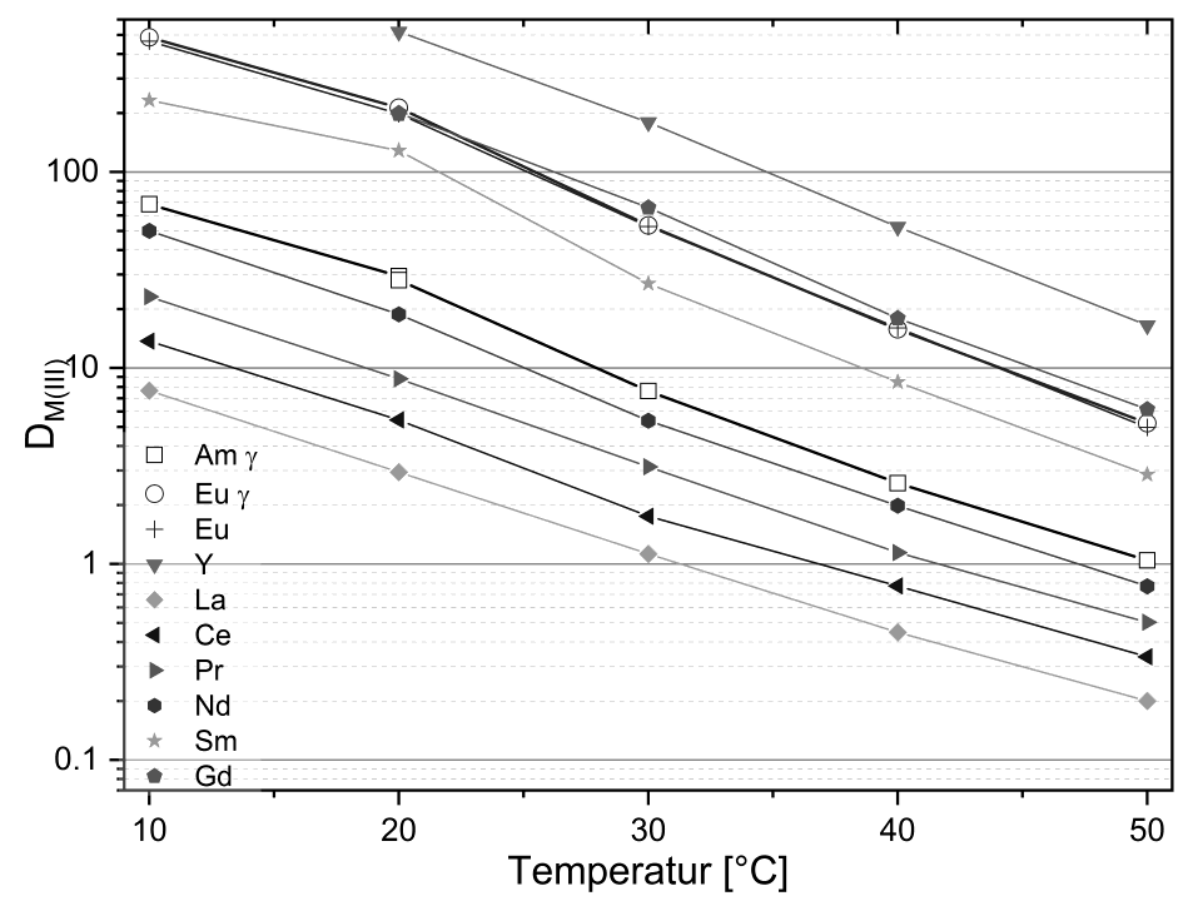

Figure 8. Distribution ratios of ${ }^{241} \mathrm{Am}(\mathrm{III}),{ }^{154} \mathrm{Eu}(\mathrm{III}), \mathrm{Y}(\mathrm{III})$ and $\mathrm{La}(\mathrm{III})-\mathrm{Gd}(\mathrm{III})$ for the extraction from $1 \mathrm{~mol} / \mathrm{L} \mathrm{HNO}_{3}$ into $0.2 \mathrm{~mol} / \mathrm{L}$ TODGA in DIPB as a function of the temperature. $A / O=1 ; t=30 \mathrm{~min}$.

Distribution ratios for all studied metal ions decrease strongly with increasing temperature (e.g.

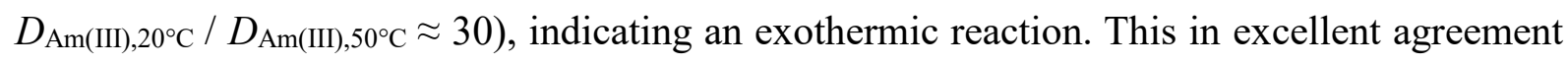
with temperature dependent Am(III) distribution data determined for a TODGA $/ n$-dodecane

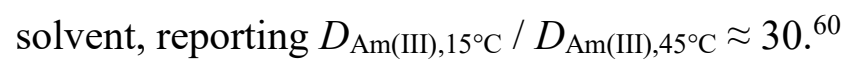

No thermodynamic evaluation of the data was performed as this would require further temperature dependent data on nitric acid extraction. Nevertheless, knowledge of the temperature effect on $\mathrm{An}(\mathrm{III})$ and $\mathrm{Ln}$ (III) extraction is mandatory for flow-sheet calculations in case a process is to be performed at a temperature other than $20^{\circ} \mathrm{C}$.

\section{Ln(III) loading behaviour}

Extracting Er(III) (initially $1.5 \mathrm{~mol} / \mathrm{L} \mathrm{Er}\left(\mathrm{NO}_{3}\right)_{3}$ in $2-4.3 \mathrm{~mol} / \mathrm{L} \mathrm{HNO}_{3}$ ) into solutions of $0.1-$ $0.5 \mathrm{~mol} / \mathrm{L}$ TODGA in DIPB did not result in the formation of a third phase or in a phase inversion. The aromatic diluent itself warrants a sufficient solubility of the nitric acid adducts and metal ion complexes; a modifier is not required.

Furthermore, a solvent comprising $0.1 \mathrm{~mol} / \mathrm{L}$ TODGA in DIPB was loaded with La(III) by extracting $\mathrm{La}\left(\mathrm{NO}_{3}\right)_{3}$ from $1 \mathrm{~mol} / \mathrm{L} \mathrm{HNO}_{3}$. Again, no third phase formation was observed at any $\mathrm{La}(\mathrm{III})$ concentration. The $\mathrm{La}(\mathrm{III})$ loading isotherm is shown in Figure 9. 


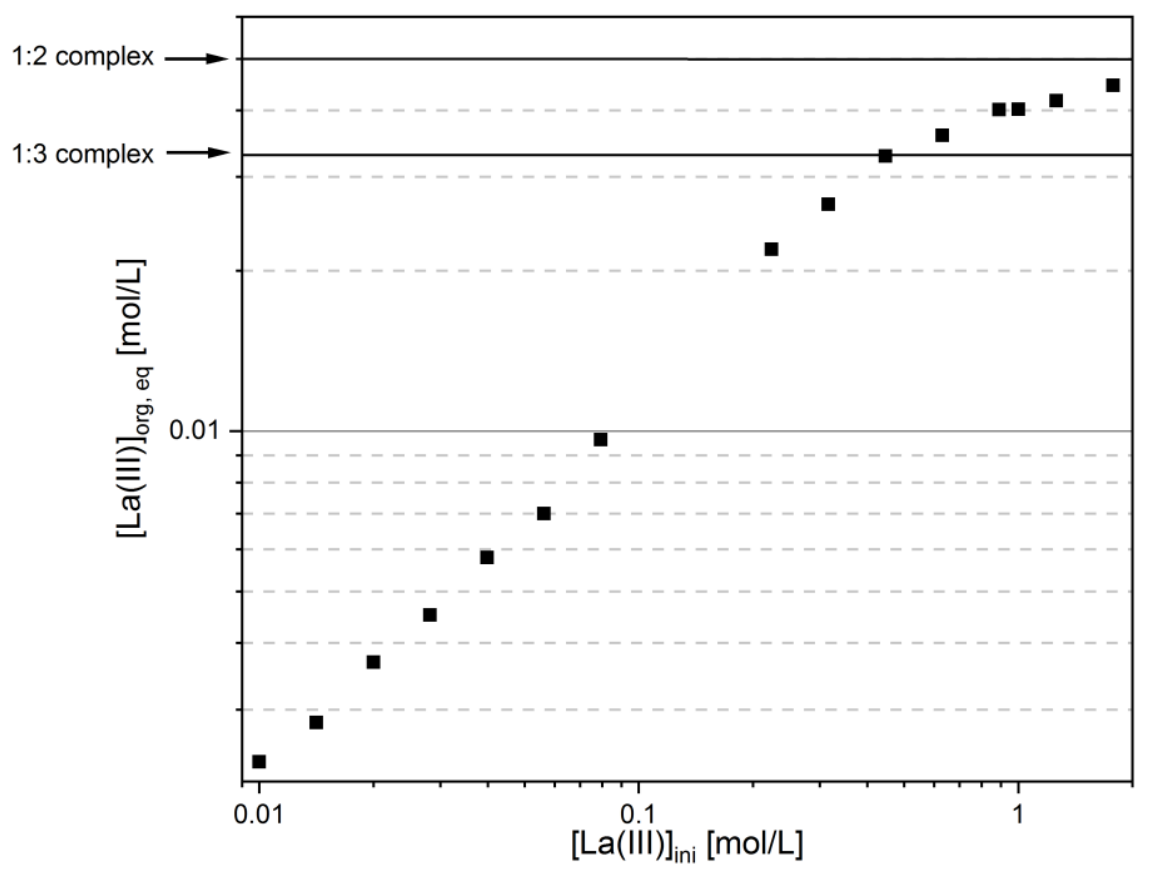

Figure 9. Loading isotherm for the extraction of $\mathrm{La}(\mathrm{III})$ from $1 \mathrm{~mol} / \mathrm{L} \mathrm{HNO}_{3}$ into $0.1 \mathrm{~mol} / \mathrm{L}$ TODGA in DIPB. $A / O=1, t=30 \mathrm{~min}, T=20^{\circ} \mathrm{C}$.

The organic equilibrium $\mathrm{La}(\mathrm{III})$ concentration increases linearly $\left(D_{\mathrm{La}(\mathrm{III})} \approx 0.15\right.$ ) with the initial $\mathrm{La}$ (III) concentration up to an aqueous initial $\mathrm{La}(\mathrm{III})$ concentration of $0.45 \mathrm{~mol} / \mathrm{L}$. At this point the organic equilibrium $\mathrm{La}(\mathrm{III})$ concentration is $0.033 \mathrm{~mol} / \mathrm{L}$. This represents the maximum concentration of $\mathrm{La}(\mathrm{III})$ extracted into $0.1 \mathrm{~mol} / \mathrm{L}$ TODGA assuming that $\mathrm{La}(\mathrm{III})$ is extracted as a 1:3 complex. However, organic equilibrium La(III) concentration keeps increasing for aqueous initial $\mathrm{La}(\mathrm{III})$ concentrations greater than $0.45 \mathrm{~mol} / \mathrm{L}$. At an aqueous initial $\mathrm{La}(\mathrm{III})$ concentration of $1.84 \mathrm{~mol} / \mathrm{L}, 0.045 \mathrm{~mol} / \mathrm{L} \mathrm{La}(\mathrm{III})$ is extracted. Consequently, lower $\mathrm{La}(\mathrm{III})$ TODGA complexes, presumably the 1:2 complex, must be present in the organic phase.

\section{Spectroscopic study of Ln(III) loaded solvent samples}

To further investigate the formation of the 1:2 complex in Ln(III) loaded organic phases, TRLFS was performed. Aqueous phases containing $1.84 \mathrm{~mol} / \mathrm{L}$ of $\mathrm{Ln}(\mathrm{III})(\mathrm{Ln}=\mathrm{Y}, \mathrm{La}, \mathrm{Nd}, \mathrm{Sm}, \mathrm{Gd}, \mathrm{Eu}$, Er) and $10^{-5} \mathrm{~mol} / \mathrm{L} \mathrm{Eu(III)} \mathrm{(in} \mathrm{case} \mathrm{of} \mathrm{Sm}(\mathrm{III}), 10^{-4} \mathrm{~mol} / \mathrm{L} \mathrm{Eu}(\mathrm{III})$ ) were prepared. After extraction and phase separation the loaded organic phases were investigated by TRLFS, focusing on the $\mathrm{Eu}(\mathrm{III})$ emission bands.

The use of two different $\mathrm{Ln}(\mathrm{III})$ per sample $\left(\mathrm{Eu}(\mathrm{III})_{\text {spike }}+\mathrm{Ln}(\mathrm{III})_{\text {excess }}\right)$ complicates the evaluation of the $\mathrm{Eu}(\mathrm{III})$ fluorescence spectra and lifetimes: $<$ 
First, the excess $\mathrm{Ln}(\mathrm{III})$ itself can fluoresce even if not excited at one of its absorption maxima. With the ratio $\left.[\text { Eu(III) })_{\text {spike }}\right]:\left[\operatorname{Ln}(I I I)_{\text {excess }}\right] \approx 10^{-5}$, extinction coefficients $\varepsilon<10^{-4} \mathrm{~mol} \cdot \mathrm{L}^{-1} \cdot \mathrm{cm}^{-1}$ are sufficient to excite $\mathrm{Ln}(\mathrm{III})_{\text {excess. }} \mathrm{Eu}$ (III) fluorescence bands overlap with $\mathrm{Nd}$ (III) and $\mathrm{Sm}$ (III) fluorescence bands. However, one can selectively detect Eu(III) fluorescence in presence of the comparatively short lived $\mathrm{Nd}(\mathrm{III})$ and $\mathrm{Sm}$ (III) fluorescence by applying a delay between excitation and fluorescence detection.

Second, a further quenching process can occur in more concentrated solutions. In dilute systems, fluorescence depends mainly on the presence of quenching molecules in the first coordination sphere of the fluorescing metal ion. Harmonic overtones of the $\mathrm{OH}$ stretching mode are the main contributors to this quenching process. However, in more concentrated solutions the excited state is additionally quenched by energy transfer via dipole-dipole coupling to neighbouring metal ions. This process is known as "Förster resonance energy transfer (FRET)". It is proportional to the inverse sixth power of the distance between the acceptor and the donor $\left(\mathrm{k}_{\mathrm{ET}} \sim \mathrm{r}_{\mathrm{AD}}{ }^{-6}\right)$. In Eu-Nd and Eu-Er systems FRET takes place from $\mathrm{Eu}(\mathrm{III})$ (donor) to $\mathrm{Nd}(\mathrm{III})$ or $\mathrm{Er}(\mathrm{III})$ (acceptors), resulting in $\mathrm{Eu}(\mathrm{III})$ fluorescence lifetimes that are shorter than expected. ${ }^{61-67}$ Consequently, Horrock's equation ${ }^{58}$ is not applicable; it over estimates the number of coordinating water molecules.

Figure 10 shows the normalized $\mathrm{Eu}$ (III) fluorescence spectra of the ${ }^{5} \mathrm{D}_{0} \rightarrow{ }^{7} \mathrm{~F}_{n}$ (top, $n=1,2$; bottom, $n=0$ ) transitions. 

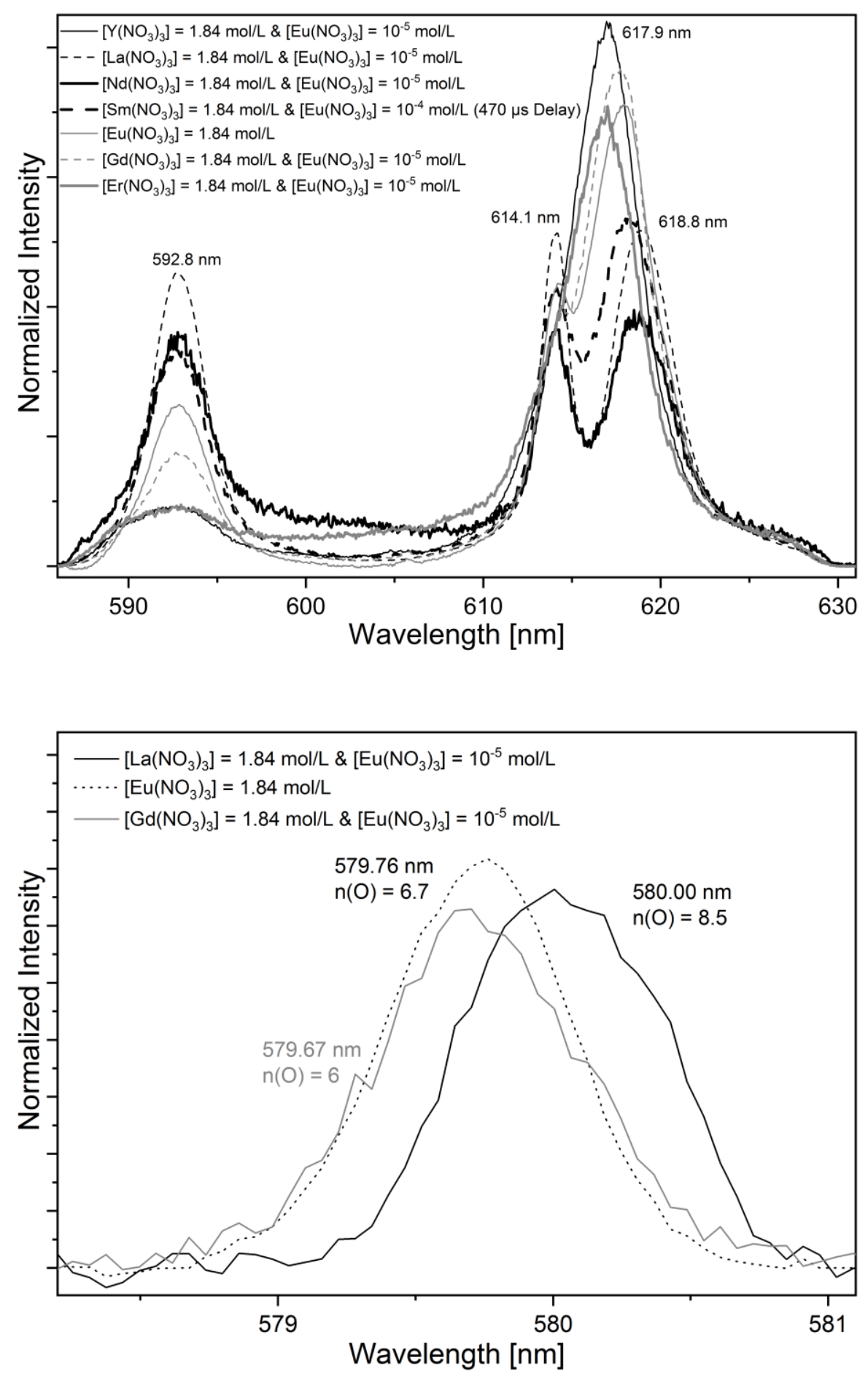

Figure 10. Normalized $\mathrm{Eu}(\mathrm{III})$ fluorescence emission spectra of the ${ }^{5} \mathrm{D}_{0} \rightarrow{ }^{7} \mathrm{~F}_{n}$ transitions (top, $n=1$, 2; bottom, $n=0$ ) of TODGA in DIPB loaded with $\mathrm{Ln}(\mathrm{III})(\mathrm{Y}, \mathrm{La}, \mathrm{Nd}, \mathrm{Sm}, \mathrm{Eu}, \mathrm{Gd}, \mathrm{Er})$. Aqueous phase, initially $1.84 \mathrm{~mol} / \mathrm{L} \mathrm{Ln}\left(\mathrm{NO}_{3}\right)_{3}$ in $1 \mathrm{~mol} / \mathrm{L} \mathrm{HNO}_{3}$. $[T O D G A]=0.1 \mathrm{~mol} / \mathrm{L}$ in DIPB; $A / O=1, t=30 \mathrm{~min}, T=20^{\circ} \mathrm{C}$.

In case of the organic phases loaded with $\mathrm{La}(\mathrm{III})$ and $\mathrm{Nd}(\mathrm{III}), \mathrm{Eu}(\mathrm{III}){ }^{5} \mathrm{D}_{0} \rightarrow{ }^{7} \mathrm{~F}_{1,2}$ emission spectra with emission bands at $592.8 \mathrm{~nm}, 614.1 \mathrm{~nm}$ and $618.8 \mathrm{~nm}$ are observed (Figure 10, top). These spectra correspond to the $\left[\mathrm{Eu}(\mathrm{TODGA})_{3}\right]^{3+}$ complex. ${ }^{54}$ However, for organic phases loaded with Y(III), Sm(III), Eu(III), Gd(III) or Er(III) an emission band at $617.9 \mathrm{~nm}$ appears, 
being most pronounced in the samples containing Y(III) and $\operatorname{Er}(\mathrm{III})$. This emission band corresponds neither to the Eu-TODGA 1:1 complex, (having an emission band at $615 \mathrm{~nm}^{54}$ ) nor to the $1: 3$ complex (cf. $\mathrm{La}(\mathrm{III})$ and $\mathrm{Nd}$ (III) samples). The observed emission band presumably belongs to the 1:2 complex. Such a 1:2 species has not been observed in earlier experiments. ${ }^{54}$ However, a similar Cm-TEDGA 1:2 complex was observed with the water soluble diglycolamide, TEDGA. ${ }^{14,55}$

$\mathrm{Eu}(\mathrm{III})$ emission spectra of the ${ }^{5} \mathrm{D}_{0} \rightarrow{ }^{7} \mathrm{~F}_{0}$ transition are shown in Figure 10 (bottom). The shift of the emission bands with respect to the emission band of the solvent spectrum $(578.9 \mathrm{~nm})$ allows calculating the number of coordinated oxygen donors. ${ }^{68}$ In case of the solvent loaded with $\mathrm{La}(\mathrm{III})$ (emission band at $580 \mathrm{~nm}$ ) the calculated number of oxygen donors is 8.5 , which is in good agreement with the $\left[\mathrm{Eu}(\mathrm{TODGA})_{3}\right]^{3+}$ complex. In case of $\mathrm{Gd}(\mathrm{III})$ and $\mathrm{Eu}(\mathrm{III})$, emission bands at $579.67 \mathrm{~nm}$ and $579.87 \mathrm{~nm}$ correspond to 6 and 6.7 TODGA oxygen donors, respectively, indicating the presence of the $1: 2 \mathrm{Eu}(\mathrm{III})$ complex.

From the Eu(III) fluorescence spectra (cf. Figure 10), three groups are distinguished:

1. Samples containing only the Eu-TODGA 1:2 complex: Y(III) and Er(III)

2. Samples containing only the Eu-TODGA 1:3 complex: La(III) and Nd(III)

3. Samples containing both 1:2 and 1:3 complexes: $\mathrm{Sm}(\mathrm{III}), \mathrm{Eu}(\mathrm{III}), \mathrm{Gd}(\mathrm{III})$

The 1:2 Eu(III)-TODGA complex is only found if the excess $\mathrm{Ln}(\mathrm{III})$ is similarly well as or better extracted than $\mathrm{Eu}(\mathrm{III})$ : The solvent is loaded with the excess $\mathrm{Ln}(\mathrm{III})$ and the remaining low concentration of free TODGA promotes the formation of the 1:2 Eu(III)-TODGA complex. In case of solvents loaded with $\mathrm{La}(\mathrm{III})$ and $\mathrm{Nd}(\mathrm{III}), \mathrm{Eu}(\mathrm{III})$ displaces $\mathrm{La}(\mathrm{III})$ or $\mathrm{Nd}(\mathrm{III})$ due to its higher distribution ratio, forming the Eu-TODGA 1:3 complex.

Fluorescence lifetime measurements of each sample were performed to further characterize the $\mathrm{Eu}(\mathrm{III})$ complexes present in the Ln(III) loaded organic phases. Results are shown in Figure 11 and are summarized in Table 1. In case of Nd(III), Gd(III) and Sm(III), bi- or triexponential fits were used to determine the lifetimes. 


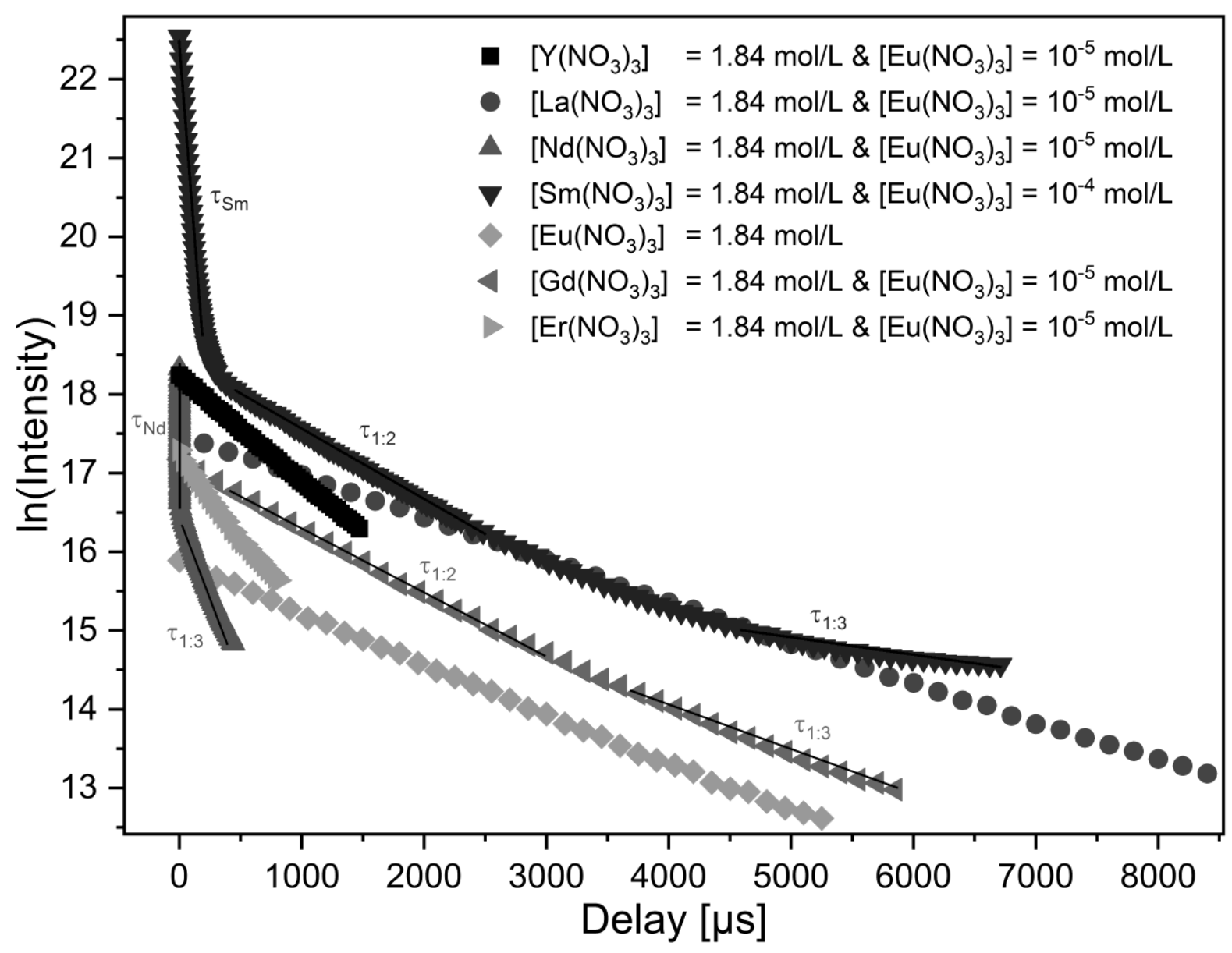

Figure 11. Natural logarithm of the Eu(III) fluorescence intensity of organic phases loaded with $\mathrm{Ln}(\mathrm{III})$ as a function of the delay time. Organic phase, $0.1 \mathrm{~mol} / \mathrm{L}$ TODGA in DIPB. Aqueous phase, $1.84 \mathrm{~mol} / \mathrm{L} \mathrm{Ln}\left(\mathrm{NO}_{3}\right)_{3}$ in $1 \mathrm{~mol} / \mathrm{L} \mathrm{HNO}_{3} . A / O=1, t=30 \mathrm{~min}, T=20^{\circ} \mathrm{C}$.

Table 1. Eu(III) and Ln(III) fluorescence lifetimes in TODGA-DIPB organic phases loaded with Ln(III) and calculated $^{58}$ number of inner-sphere water molecules of the Eu(III)-TODGA complexes.

\begin{tabular}{lll}
\hline $\mathbf{L n}(\mathbf{I I I})$ & Lifetimes $[\boldsymbol{\mu s}]$ & $\boldsymbol{n}\left(\mathbf{H}_{\mathbf{2}} \mathbf{O}\right)$ \\
\hline $\mathrm{Y}$ & $\tau_{\mathrm{Eu}}=758 \pm 25$ & 0.8 \\
$\mathrm{La}$ & $\tau_{\mathrm{Eu}}=1929 \pm 42$ & -0.1 \\
$\mathrm{Nd}$ & $\tau_{\mathrm{Nd}}=1.50 \pm 0.03 ; \tau_{\mathrm{Eu}}=265 \pm 15$ & 3.4 \\
$\mathrm{Sm}$ & $\tau_{\mathrm{Sm}}=44 \pm 4 ; \tau_{\mathrm{Eu}}=1094 \pm 28$ and $3424 \pm 105$ & $0.3(1: 2) ;-0.3(1: 3)$ \\
$\mathrm{Eu}$ & $\tau_{\mathrm{Eu}}=1585 \pm 35$ & 0.1 \\
$\mathrm{Gd}$ & $\tau_{\mathrm{Eu}}=926 \pm 27$ and $1929 \pm 41$ & $0.5(1: 2),-0.1(1: 3)$ \\
$\mathrm{Er}$ & $\tau_{\mathrm{Eu}}=446 \pm 20$ & 1.7 \\
\hline
\end{tabular}

Both $\mathrm{Nd}(\mathrm{III})$ and $\mathrm{Sm}(\mathrm{III})$ are excited by the laser light having a wavelength of $\lambda_{\text {ex }}=394 \mathrm{~nm}$. The fluorescence lifetimes $\tau_{\mathrm{Nd}}$ and $\tau_{\mathrm{Sm}}$ are in the usual range of those observed in organic solutions $\left(0.032 \mu \mathrm{s}<\tau_{\mathrm{Nd}}<2 \mu \mathrm{s}^{69-70}\right.$ and $\left.2.7 \mu \mathrm{s}<\tau_{\mathrm{Sm}}<22 \mu \mathrm{s}\right) .{ }^{69}$ The lifetimes of the Eu(III)- 
TODGA complexes indicate the absence of coordinating water molecules, with the exception of the solvents loaded with $\mathrm{Y}(\mathrm{III})\left(\approx 1 \mathrm{H}_{2} \mathrm{O}\right), \mathrm{Nd}(\mathrm{III})\left(\approx 3 \mathrm{H}_{2} \mathrm{O}\right)$ and $\operatorname{Er}(\mathrm{III})\left(\approx 2 \mathrm{H}_{2} \mathrm{O}\right)$. Shorter lifetimes in case of $\mathrm{Nd}(\mathrm{III})$ and $\operatorname{Er}(\mathrm{III})$ may be caused by quenching via Förster resonance energy transfer.

The lifetimes of the Eu-TODGA 1:3 complexes are in the range of $1929 \mu \mathrm{s}<\tau_{1: 3}<3424 \mu \mathrm{s}$. This corresponds to zero water molecules in the first coordination sphere. Lifetimes of the 1:2 complex are in the range of $758 \mu \mathrm{s}<\tau_{1: 2}<1094 \mu \mathrm{s}$, corresponding to $0.8-0.3$ water molecules in the first coordination sphere.

Six coordination sites of $\mathrm{Eu}(\mathrm{III})$ are occupied by the tridentate TODGA ligands in the 1:2 complex. With $\mathrm{Eu}(\mathrm{III})$ preferring nine-fold coordination in solution, three sites are available for further ligands. As the aromatic diluent is inert, only nitrate or, according to the lifetime, zero or one water molecule may fill the vacant sites (cf. Table 1). Consequently, the 1:2 complex is $\left[\mathrm{Eu}(\mathrm{TODGA})_{2}\left(\mathrm{H}_{2} \mathrm{O}\right)\left(\mathrm{NO}_{3}\right)_{m}\right]^{(3-m)+}(m=1,2)$ or $\left[\mathrm{Eu}(\mathrm{TODGA})_{2}\left(\mathrm{NO}_{3}\right)_{n}\right]^{(3-n)^{+}}(n=2,3)$ in the organic phase ( $m, n$ depending on the denticity $\kappa$ of the nitrate anion). Whatever the exact stoichiometry of the 1:2 complex might be, it is clearly distinguished from the 1:3 complex by its $\mathrm{Eu}(\mathrm{III})$ emission spectrum.

To investigate the formation of the 1:2 complex in other than aromatic diluents, similar loading experiments were conducted using $0.1 \mathrm{~mol} / \mathrm{L}$ TODGA dissolved in TPH +5 vol. $\%$ 1-octanol. $\mathrm{Eu}$ (III) spectra in TPH/1-octanol (dashed lines) are compared to the spectra in DIPB (continuous lines) in the SI, Figure S7. No significant differences are observed for any of the samples, confirming the formation of a 1:2 complex also in the aliphatic diluent. Fluorescence lifetimes similar to those measured in the TODGA-DIPB solvent (SI, Figure S8) further confirm this observation.

These results represent the first spectroscopic evidence of a Eu(III)-TODGA 1:2 complex in loaded organic phases, independent of the diluent. Eu(III) emission spectra confirm that the new species is a 1:2 complex. This explains the observed high $\operatorname{Ln}(\mathrm{III})$ concentrations in the organic phase of the La(III) loading experiment (cf. Figure 9). The existence of this 1:2 TODGA complex must be considered when discussing extraction data and taken into account for DGA equilibrium and flow-sheet models.

\section{CONCLUSION}

The extraction of nitric acid, An(III) and Ln(III) into TODGA dissolved in aromatic diluents (DIPB, tBuB) was studied. Compared to TODGA-kerosene solvents, ${ }^{3-4,6,25}$ the TODGA-DIPB solvent extracts less nitric acid, and $\mathrm{An}(\mathrm{III})$ and $\mathrm{Ln}$ (III) distribution ratios are one to two orders 
of magnitude lower for a given nitric acid concentration. Hence, higher ligand concentrations can be used which benefits metal ion loading. No third phase formation was observed.

Slope analysis implies that Am(III) is extracted as a 1:4 or 1:3 complex, depending on nitric acid concentration. TRLFS shows the inner coordination sphere of these complexes to be $\left[\mathrm{M}(\mathrm{DGA})_{3}\right]^{3+}(\mathrm{M}=\mathrm{Cm}, \mathrm{Eu})$. TRLFS investigations of organic phases loaded with $\mathrm{Ln}(\mathrm{III})$ reveal the formation of the Eu(III)-TODGA 1:2 complex for the first time.

In summary, the TODGA-DIPB solvent allows for high $\mathrm{Ln}(\mathrm{III})$ loading without requiring a phase modifier, other than kerosene-based TODGA solvents. This solvent shows potential in the context of both rare earth recycling and advanced nuclear fuel cycles.

\section{AUTHOR INFORMATION}

\section{Corresponding Author}

Patrik Weßling, Karlsruhe Institute for Technology (KIT), Institute for Nuclear Waste Disposal (INE), P. O. Box 3640, 76021 Karlsruhe, Germany, +4972160824652, patrik.wessling@kit.edu

\section{Author Contributions}

All authors have given approval to the final version of the manuscript. All authors contributed equally.

\section{Funding Sources}

This work has received funding from the European Research Council (ERC) under the European Union's Horizon 2020 research and innovation program (project GENIORS, grant agreement $\mathrm{N}^{\circ} 755171$ ).

\section{Notes}

The authors declare no competing financial interests.

\section{REFERENCES}

1. Stephan, H.; Gloe, K.; Beger, J.; Mühl, P., Liquid-liquid extraction of metal ions with amido podands. Solvent Extr. Ion Exch. 1991, 9 (3), 459-469.

2. Sasaki, Y.; Choppin, G. R., Solvent extraction of Eu, Th, U, Np and Am with N,N'-dimethyl-N,N'dihexyl-3-oxapentanediamide and its analogous compounds. Analytical Sciences 1996, 12 (2), 225-230. 
3. Sasaki, Y.; Sugo, Y.; Suzuki, S.; Tachimori, S., The novel extractants, diglycolamides, for the extraction of lanthanides and actinides in HNO3/n-dodecane system. Solvent Extr Ion Exc 2001, 19 (1), 91-103.

4. Modolo, G.; Asp, H.; Schreinemachers, C.; Vijgen, H., Development of a TODGA based process for partitioning of actinides from a PUREX raffinate part I: batch extraction optimization studies and stability tests. Solvent Extr. Ion Exch. 2007, 25 (6), 703-721.

5. Whittaker, D.; Geist, A.; Modolo, G.; Taylor, R.; Sarsfield, M.; Wilden, A., Applications of diglycolamide based solvent extraction processes in spent nuclear fuel reprocessing, part 1: TODGA. Solvent Extr Ion Exc 2018, 36 (3), 223-256.

6. Woodhead, D.; McLachlan, F.; Taylor, R.; Müllich, U.; Geist, A.; Wilden, A.; Modolo, G., Nitric acid extraction into a TODGA solvent modified with 1-octanol. Solvent Extr. Ion Exch. 2019, 37 (2), 173-190.

7. Carrott, M.; Geist, A.; Hérès, X.; Lange, S.; Malmbeck, R.; Miguirditchian, M.; Modolo, G.; Wilden, A.; Taylor, R., Distribution of plutonium, americium and interfering fission products between nitric acid and a mixed organic phase of TODGA and DMDOHEMA in kerosene, and implications for the design of the "EUROGANEX" process. Hydrometallurgy 2015, 152, 139-148.

8. $\quad$ Ansari, S. A.; Pathak, P.; Mohapatra, P. K.; Manchanda, V. K., Chemistry of diglycolamides: promising extractants for actinide partitioning. Chem Rev 2012, 112 (3), 1751-1772.

9. Sasaki, Y.; Suzuki, H.; Sugo, Y.; Kimura , T.; Choppin, G. R., New Water-soluble organic ligands for actinide cations complexation. Chemistry Letters 2006, 35 (3), 256-257.

10. Reilly, S. D.; Gaunt, A. J.; Scott, B. L.; Modolo, G.; Iqbal, M.; Verboom, W.; Sarsfield, M. J., Plutonium(IV) complexation by diglycolamide ligands-coordination chemistry insight into TODGA-based actinide separations. Chem. Commun. 2012, 48 (78), 9732-9734.

11. Sasaki, Y.; Sugo, Y.; Morita, K.; Nash, K. L., The effect of alkyl substituents on actinide and lanthanide extraction by diglycolamide compounds. Solvent Extr. Ion Exch. 2015, 33 (7), 625-641.

12. Charbonnel, M. C.; Berthon, C.; Berthon, L.; Boubals, N.; Burdet, F.; Duchesne, M. T.; Guilbaud, P.; Mabille, N.; Petit, S.; Zorz, N., Complexation of Ln(III) and Am(III) with the hydrosoluble TEDGA: speciation and thermodynamics studies. Proc. Chem. 2012, 7, 20-26.

13. Lange, S.; Wilden, A.; Modolo, G.; Sadowski, F.; Gerdes, M.; Bosbach, D., Direct selective extraction of trivalent americium from PUREX raffinate using a combination of CyMe4BTPhen and TEDGA — a feasibility study. Solvent Extr. Ion Exch. 2017, 35 (3), 161-173.

14. Klaß, L.; Wilden, A.; Sadowski, F.; Wagner, C.; Geist, A.; Panak, P. J.; Herdzik-Koniecko, I.; Narbutt, J.; Modolo, G., Evaluation of the hydrophilic complexant N,N,N',N'-tetraethyldiglycolamide (TEDGA) and its methyl-substituted analogues in the selective Am(III) separation. Solvent Extr. Ion Exch. 2018, (accepted).

15. Manohar, S.; Sharma, J. N.; Shah, B. V.; Wattal, P. K., Process development for bulk separation of trivalent actinides and lanthanides from radioactive high-level liquid waste. Nucl. Sci. Eng. 2007, 156 (1), 96-102.

16. Magnusson, D.; Christiansen, B.; Glatz, J. P.; Malmbeck, R.; Modolo, G.; Serrano-Purroy, D.; Sorel, C., Demonstration of a TODGA based extraction process for the partitioning of minor actinides from a PUREX raffinate. Part III: centrifugal contactor run using genuine fuel solution. Solvent Extr. Ion Exch. 2009, 27 (1), 2635.

17. Wilden, A.; Modolo, G.; Kaufholz, P.; Sadowski, F.; Lange, S.; Sypula, M.; Magnusson, D.; Müllich, U.; Geist, A.; Bosbach, D., Laboratory-scale counter-current centrifugal contactor demonstration of an innovativeSANEX process using a water soluble BTP. Solvent Extr. Ion Exch. 2015, 33 (2), 91-108.

18. Carrott, M.; Bell, K.; Brown, J.; Geist, A.; Gregson, C.; Hérès, X.; Maher, C.; Malmbeck, R.; Mason, C.; Modolo, G.; Müllich, U.; Sarsfield, M.; Wilden, A.; Taylor, R., Development of a new flowsheet for co-separating the transuranic actinides: the "EURO-GANEX" process. Solvent Extr. Ion Exch. 2014, 32 (5), 447-467. 
19. Malmbeck, R.; Magnusson, D.; Bourg, S.; Carrott, M.; Geist, A.; Hérès, X.; Miguirditchian, M.; Modolo, G.; Müllich, U.; Sorel, C.; Taylor, R.; Wilden, A., Homogenous recycling of transuranium elements from irradiated fast reactor fuel by the EURO-GANEX solvent extraction process. Radiochim. Acta 2019, 107 (9-11), 917-929.

20. Modolo, G.; Geist, A.; Miguirditchian, M., Minor actinide separations in the reprocessing of spent nuclear fuels: recent advances in Europe. In Reprocessing and Recycling of Spent Nuclear Fuel, Taylor, R., Ed. Woodhead Publishing: Cambridge, UK, 2015.

21. Poinssot, C.; Warin, D.; Rostaing, C., Recent achievements towards the recycling of minor actinides for the improvement of future nuclear fuel cycle. In Transactions of European Nuclear Conference, Barcelona, Spain, 30 May - 2 June, 2010; pp 419-425.

22. Bourg, S.; Hill, C.; Caravaca, C.; Rhodes, C.; Ekberg, C.; Taylor, R.; Geist, A.; Modolo, G.; Cassayre, L.; Malmbeck, R.; Harrison, M.; de Angelis, G.; Espartero, A.; Bouvet, S.; Ouvrier, N., ACSEPT—Partitioning technologies and actinide science: Towards pilot facilities in Europe. Nucl. Eng. Des. 2011, 241 (9), 3427-3435.

23. Bourg, S.; Geist, A.; Narbutt, J., SACSESS - the EURATOM FP7 project on actinide separation from spent nuclear fuels. Nukleonika 2015, 60 (4), 809-814.

24. Bourg, S.; Geist, A.; Adnet, J.-M.; Rhodes, C.; Hanson, B., GENIORS, a new European project addressing Gen IV integrated oxide fuels recycling strategies. In Proc. Internat. Conf. GLOBAL 2017 (Nuclear Energy Innovation to the Carbon-Free World), Seoul, Korea, 24-29 September, 2017.

25. Geist, A.; Müllich, U.; Magnusson, D.; Kaden, P.; Modolo, G.; Wilden, A.; Zevaco, T., Actinide(III)/Lanthanide(III) Separation Via Selective Aqueous Complexation of Actinides(III) using a Hydrophilic 2,6-Bis(1,2,4-Triazin-3-Yl)-Pyridine in Nitric Acid. Solvent Extr Ion Exc 2012, 30 (5), 433-444.

26. Sypula, M.; Wilden, A.; Schreinemachers, C.; Malmbeck, R.; Geist, A.; Taylor, R.; Modolo, G., Use of polyaminocarboxylic acids as hydrophilic masking agents for fission products in actinide partitioning processes. Solvent Extr. Ion Exch. 2012, 30 (7), 748-764.

27. Wagner, C.; Müllich, U.; Geist, A.; Panak, P. J., Selective Extraction of Am(III) from PUREX Raffinate: The AmSel System. Solvent Extr Ion Exc 2016, 34 (2), 103-113.

28. Macerata, E.; Mossini, E.; Scaravaggi, S.; Mariani, M.; Mele, A.; Panzeri, W.; Boubals, N.; Berthon, L.; Charbonnel, M.-C.; Sansone, F.; Arduini, A.; Casnati, A., Hydrophilic Clicked 2,6-Bis-triazolyl-pyridines Endowed with High Actinide Selectivity and Radiochemical Stability: Toward a Closed Nuclear Fuel Cycle. $J A m$ Chem Soc 2016, 138 (23), 7232-7235.

29. Mossini, E.; Macerata, E.; Wilden, A.; Kaufholz, P.; Modolo, G.; Iotti, N.; Casnati, A.; Geist, A.; Mariani, M., Optimization and single-stage centrifugal contactor experiments with the novel hydrophilic complexant PyTriDiol for the i-SANEX process. Solvent Extr. Ion Exch. 2018, 36 (4), 373-386.

30. Marie, C.; Kaufholz, P.; Vanel, V.; Duchesne, M.-T.; Russello, E.; Faroldi, F.; Baldini, L.; Casnati, A.; Wilden, A.; Modolo, G.; Miguirditchian, M., Development of a selective americium separation process using H4TPAEN as water-soluble stripping agent. Solvent Extr. Ion Exch. 2019, 37 (5), 313-327.

31. Tachimori, S.; Sasaki, Y.; Suzuki, S.-I., Modification of TODGA-n-dodecane solvent with a monoamide for high loading of lanthanides(III) and actinides(III). Solvent Extr. Ion Exch. 2002, 20 (6), 687-699.

32. Berthon, L.; Morel, J. M.; Zorz, N.; Nicol, C.; Virelizier, H.; Madic, C., Diamex process for minor actinide partitioning: Hydrolytic and radiolytic degradations of malonamide extractants. Separ Sci Technol 2001, $36(5-6), 709-728$.

33. Geist, A.; Berthon, L.; Charbonnel, M.-C.; Müllich, U., Extraction of nitric acid, nmericium(III), curium(III) and lanthanides(III) into DMDOHEMA dissolved in kerosene. Solvent Extr. Ion Exch. 2019, (submitted). 
34. Brown, J.; McLachlan, F.; Sarsfield, M.; Taylor, R.; Modolo, G.; Wilden, A., Plutonium loading of prospective grouped actinide extraction (GANEX) solvent systems based on diglycolamide extractants. Solvent Extr. Ion Exch. 2012, 30 (2), 127-141.

35. Geist, A., Extraction of nitric acid into alcohol:kerosene mixtures. Solvent Extr. Ion Exch. 2010, 28 (5), 596-607.

36. Ansari, S. A.; Pathak, P. N.; Manchanda, V. K.; Husain, M.; Prasad, A. K.; Parmar, V. S., N,N,N',N'tetraoctyl diglycolamide (TODGA): a promising extractant for actinide partitioning from high-level waste (HLW). Solvent Extr Ion Exc 2005, 23 (4), 463-479.

37. Xu, Y.; Gao, Y.; Zhou, Y.; Fan, C.; Hou, H.; Zhang, M., Extraction behavior of strontium from nitric acid medium with N,N'-dimethyl-N,N'-dioctyldiglcolamide. Solvent Extr. Ion Exch. 2017, 35 (7), 507-518.

38. Campbell, E. L.; Holfeltz, V. E.; Hall, G. B.; Nash, K. L.; Lumetta, G. J.; Levitskaia, T. G., Nitric acid and water extraction by T2EHDGA in n-dodecane. Solvent Extr. Ion Exch. 2017, 35 (7), 586-603.

39. Malmbeck, R.; Magnusson, D.; Geist, A., Modified diglycolamides for grouped actinide separation. $J$. Radioanal. Nucl. Chem. 2017, 314 (3), 2531-2538.

40. Iqbal, M.; Huskens, J.; Verboom, W.; Sypula, M.; Modolo, G., Synthesis and Am/Eu extraction of novel TODGA derivatives. Supramolec. Chem. 2010, 22 (11/12), 827-837.

41. Wilden, A.; Kowalski, P. M.; Klaß, L.; Kraus, B.; Kreft, F.; Modolo, G.; Li, Y.; Rothe, J.; Dardenne, K.; Geist, A.; Leoncini, A.; Huskens, J.; Verboom, W., Unprecedented inversion of selectivity and extraordinary difference in the complexation of trivalent $\mathrm{f}$ elements by diastereomers of a methylated diglycolamide. Chem. Eur. J. 2019, 25 (21), 5507-5513.

42. Blake, C. A.; Baes, C. F.; Brown, K. B., Solvent extraction with alkyl phosphoric compounds. Industrial \& Engineering Chemistry 1958, 50 (12), 1763-1767.

43. Kolarik, Z.; Müllich, U.; Gassner, F., Extraction of Am(III) and Eu(III) nitrates by 2,6-di-(5,6-dipropyl1,2,4-triazin-3-yl)pyridines. Solvent Extr. Ion Exch. 1999, 17 (5), 1155-1170.

44. Mincher, B. J.; Modolo, G.; Mezyk, S. P., Review: the effects of radiation chemistry on solvent extraction 4: separation of the trivalent actinides and considerations for radiation-resistant solvent systems. Solvent Extr. Ion Exch. 2010, 28 (4), 415-436.

45. Canva, J.; Pagès, M., Effets de protection et de sensibilisation dans la décomposition radiolytique du phosphate de tributyle. Radiochim. Acta 1965, 4 (2), 88-91.

46. Stephan, H.; Gloe, K.; Beger, J.; Mühl, P., Liquid-liquid extraction of strontium with amido podands. Solvent Extr. Ion Exch. 1991, 9 (3), 435-458.

47. Sasaki, Y.; Choppin, G. R., Extraction of Np(V) by N,N'-dimethyl-N,N'-dihexyl-3-oxapentanediamide. Radiochim. Acta 1998, 80 (2), 85-88.

48. Weaver, B.; Kappelmann, F. A. TALSPEAK: a new method of separating americium and curium from the lanthanides by extraction from an aqueous solution of an aminopolyacetic acid complex with a monoacidic organophosphate or phosphonate; USAEC report ORNL-3559, Oak Ridge National Laboratory, USA: 1964.

49. Weaver, B.; Kappelmann, F. A., Preferential extraction of lanthanides over trivalent actinides by monoacidic organophosphates from carboxylic acids and from mixtures of carboxylic and aminopolyacetic acids. Journal of Inorganic and Nuclear Chemistry 1968, 30 (1), 263-272.

50. Modolo, G.; Seekamp, S.; Nabet, S., Development of an extraction process for separation of actinoids(III)/lanthanoids(III) with the aid of dithiophosphinic acids. Chem. Ing. Tech. 2002, 74 (3), 261-265.

51. Modolo, G.; Kluxen, P.; Geist, A., Demonstration of the LUCA process for the separation of americium(III) from curium(III), californium(III), and lanthanides(III) in acidic solution using a synergistic 
mixture of bis(chlorophenyl)dithiophosphinic acid and tris(2-ethylhexyl)phosphate. Radiochim. Acta 2010, 98 (4), $193-201$.

52. Ciavatta, L., The specific interaction theory in the evaluating ionic equilibria. Ann. Chim. (Rome) 1980, $70,551-562$.

53. Guillaumont, R.; Fanghänel, T.; Fuger, J.; Grenthe, I.; Neck, V.; Palmer, D. A.; Rand, M. H., Chemical Thermodynamics (OECD-NEA TDB). Elsevier: Amsterdam, 2003; Vol. 5.

54. Wilden, A.; Modolo, G.; Lange, S.; Sadowski, F.; Beele, B. B.; Skerencak-Frech, A.; Panak, P. J.; Iqbal, M.; Verboom, W.; Geist, A.; Bosbach, D., Modified diglycolamides for the An(III) + Ln(III) co-separation: evaluation by solvent extraction and time-resolved laser fluorescence spectroscopy. Solvent Extr. Ion Exch. 2014, 32 (2), 119-137.

55. Herdzik-Koniecko, I.; Wagner, C.; Trumm, M.; Müllich, U.; Schimmelpfennig, B.; Narbutt, J.; Geist, A.; Panak, P. J., Do An(III) and Ln(III) ions form heteroleptic complexes with diglycolamide and hydrophilic BT(B)P ligands in solvent extraction systems? A spectroscopic and DFT study. New J. Chem. 2019, 43 (16), 6314-6322.

56. Wagner, C.; Mossini, E.; Macerata, E.; Mariani, M.; Arduini, A.; Casnati, A.; Geist, A.; Panak, P. J., Time-resolved laser fluorescence spectroscopy study of the coordination chemistry of a hydrophilic CHON [1,2,3triazol-4-yl]pyridine ligand with $\mathrm{Cm}(\mathrm{III})$ and $\mathrm{Eu}(\mathrm{III})$. Inorg. Chem. 2017, 56 (4), 2135-2144.

57. Kimura, T.; Choppin Gregory, R.; Kato, Y.; Yoshida, Z., Determination of the hydration number of $\mathrm{Cm}(\mathrm{III})$ in various aqueous solutions. Radiochim. Acta 1996, 72 (2), 61-64.

58. Horrocks, W. D.; Sudnick, D. R., Lanthanide ion probes of structure in biology - laser-induced luminescence decay constants provide a direct measure of the number of metal-coordinated water molecules. $J$. Amer. Chem. Soc. 1979, 101 (2), 334-340.

59. Shimojo, K.; Kurahashi, K.; Naganawa, H., Extraction behavior of lanthanides using a diglycolamide derivative TODGA in ionic liquids. Dalton Trans. 2008, (37), 5083-5088.

60. Ansari, S. A.; Pathak, P. N.; Husain, M.; Prasad, A. K.; Parmar, V. S.; Manchanda, V. K., Extraction of actinides using $\mathrm{N}, \mathrm{N}, \mathrm{N}^{\prime}, \mathrm{N}^{\prime}$-tetraoctyl diglycolamide (TODGA): a thermodynamic study. Radiochim. Acta 2006, 94 (6-7), 307-312.

61. Nakazawa, E.; Shionoya, S., Energy Transfer between Trivalent Rare-Earth Ions in Inorganic Solids. The Journal of Chemical Physics 1967, 47 (9), 3211-3219.

62. Horrocks, W. D.; Rhee, M.-J.; Snyder, A. P.; Sudnick, D. R., Laser-induced metal ion luminescence: interlanthanide ion energy transfer distance measurements in the calcium-binding proteins, parvalbumin, and thermolysin. Metalloprotein models address a photophysical problem. J. Amer. Chem. Soc. 1980, 102 (10), 36503652 .

63. Tanaka, F.; Ishibashi, T., Energy transfer between lanthanide ions in dinuclear complexes. Journal of the Chemical Society, Faraday Transactions 1996, 92 (7), 1105-1110.

64. Annapurna, K.; Dwivedi, R. N.; Buddhudu, S., Energy transfer luminescence in (Eu3+,Nd3+) : tellurite glass. Optical Materials 2000, 13 (4), 381-388.

65. Lis, S.; Elbanowski, M.; Mąkowska, B.; Hnatejko, Z., Energy transfer in solution of lanthanide complexes. Journal of Photochemistry and Photobiology A: Chemistry 2002, 150 (1-3), 233-247.

66. Min, X.; Huang, Z.; Fang, M.; Liu, Y.-G.; Tang, C.; Wu, X., Energy transfer from Sm3+ to Eu3+ in redemitting phosphor LaMgAl11O19:Sm3+, Eu3 + for solar cells and near-utraviolet white light-emitting diodes. Inorg. Chem. 2014, 53 (12), 6060-6065.

67. Abad Galán, L.; Sobolev, A. N.; Skelton, B. W.; Zysman-Colman, E.; Ogden, M. I.; Massi, M., Energy transfer between $\mathrm{Eu} 3+$ and $\mathrm{Nd} 3+$ in near-infrared emitting $\beta$-triketonate coordination polymers. Dalton Trans. 2018, 47 (35), 12345-12352. 
68. Choppin, G. R.; Wang, Z. M., Correlation between ligand coordination number and the shift of the 7F0-5D0 transition frequency in europium(III) complexes. Inorg. Chem. 1997, 36 (2), 249-252.

69. Kimura, T.; Nagaishi, R.; Kato, Y.; Yoshida, Z., Luminescence study on solvation of americium(III), curium(III) and several lanthanide(III) ions in nonaqueous and binary mixed solvents. Radiochim. Acta 2001, 89 (3), 125-130.

70. Bünzli, J.-C.; Vuckovic, M. M., Solvation of neodymium(III) perchlorate and nitrate in organic solvents as determined by spectroscopic measurements. Inorg. Chim. Acta. 1984, 95 (2), 105-112. 


\section{Application of TODGA Solvents for An(III) and Ln(III) Extraction Requiring no Modifier to Suppress Third Phase Formation}

\section{- Supplementary Information -}

Patrik Weßling,*,a,b Udo Müllich, ${ }^{\text {a }}$ Elise Guerinoni, ${ }^{\mathrm{c}}$ Andreas Geist, ${ }^{\text {a }}$ and Petra J. Panak $^{\mathrm{a}, \mathrm{b}}$

${ }^{\text {a }}$ Karlsruhe Institute of Technology (KIT), Institute for Nuclear Waste Disposal (INE), P. O. Box 3640, 76021 Karlsruhe, Germany

${ }^{\mathrm{b}}$ Ruprecht-Karls-Universität Heidelberg, Institut für Physikalische Chemie, Im Neuenheimer Feld 253, 69120 Heidelberg, Germany

${ }^{\mathrm{c}}$ École Nationale Supérieure de Chimie de Montpellier, France

Extraction kinetics of ${ }^{241} \mathrm{Am}(\mathrm{III})$ and ${ }^{154} \mathrm{Eu}(\mathrm{III})$ with TODGA in DIPB

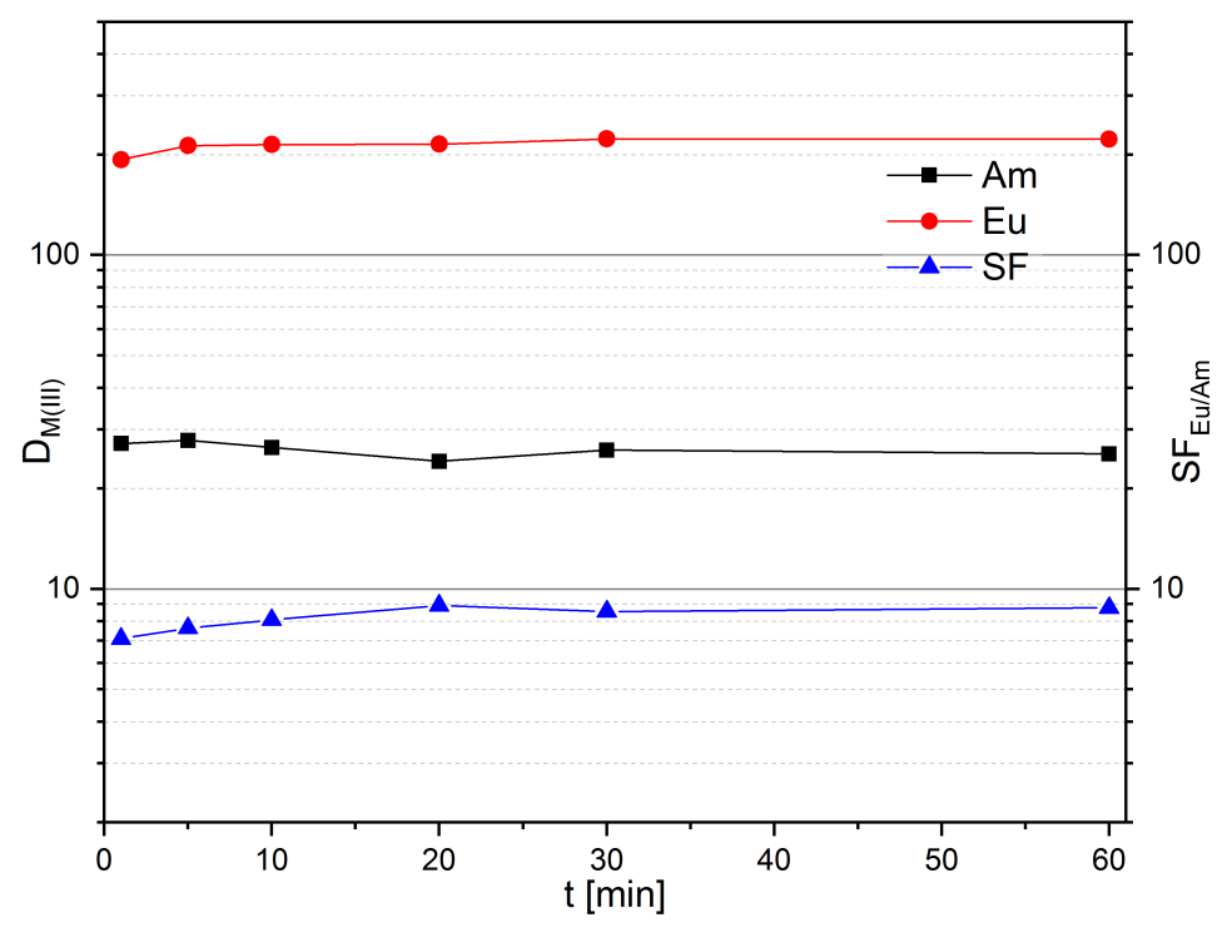

Fig. S1. ${ }^{241} \mathrm{Am}(\mathrm{III})$ and ${ }^{154} \mathrm{Eu}(\mathrm{III})$ distribution ratios for the extraction with TODGA dissolved in DIPB as a function of shaking time. $\left[H N O_{3}\right]_{\mathrm{ini}}=1 \mathrm{~mol} / \mathrm{L} ;[T O D G A]=0.2 \mathrm{~mol} / \mathrm{L} ; A / O=1 ; T=20^{\circ} \mathrm{C}$. 
Normalized Cm(III) and Eu(III) fluorescence spectra of the organic phase of TODGA extraction samples in aromatic diluents.
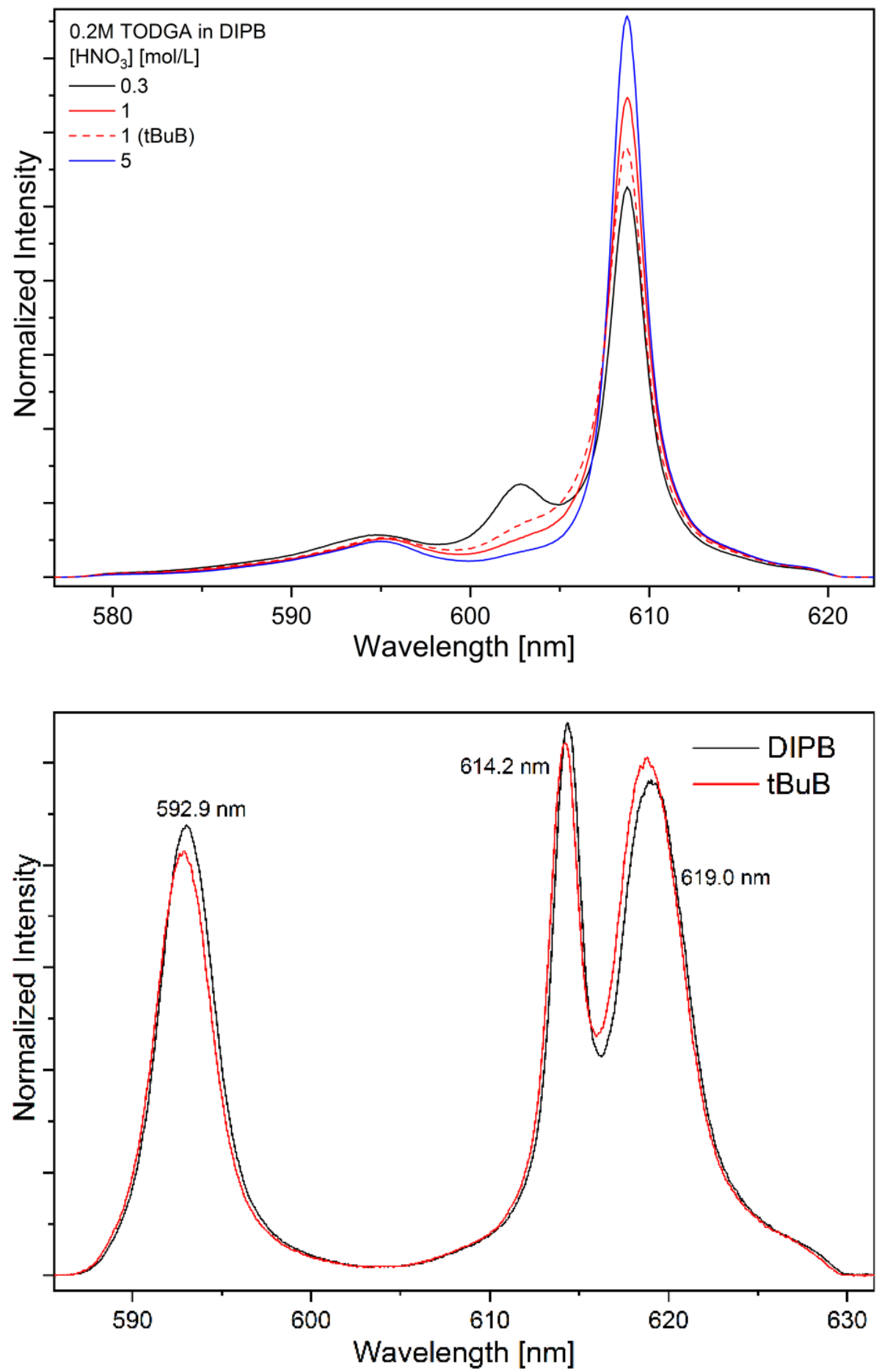

Fig. S2. Normalized fluorescence spectra (top, $\mathrm{Cm}$ (III) ${ }^{6} \mathrm{D}^{{ }_{7 / 2}} \rightarrow{ }^{8} \mathrm{~S}_{7 / 2}$; right, Eu(III) ${ }^{5} \mathrm{D}_{0} \rightarrow{ }^{7} \mathrm{~F}_{n}(n=1,2)$ ) of organic phases from the extraction of $\mathrm{Cm}(\mathrm{III})$ or $\mathrm{Eu}(\mathrm{III})$ with $0.2 \mathrm{~mol} / \mathrm{L}$ TODGA dissolved in DIPB or tBuB. $[C m(I I I)]_{\text {ini }}=10^{-7} \mathrm{~mol} / \mathrm{L} ;[E u(I I I)]_{\text {ini }}=10^{-5} \mathrm{~mol} / \mathrm{L}\left[H N O_{3}\right]_{\text {ini }}=0.3-5 \mathrm{~mol} / \mathrm{L}$ (in case of $\mathrm{Eu}(I I I): 1 \mathrm{~mol} / \mathrm{L}$ ); $A / O=1 ; t=30 \mathrm{~min} ; T=20^{\circ} \mathrm{C}$. 
$\mathrm{Cm}$ (III) and $\mathrm{Eu}$ (III) fluorescence lifetime of the organic phases of extraction samples for the extraction with TODGA in DIPB or tBuB
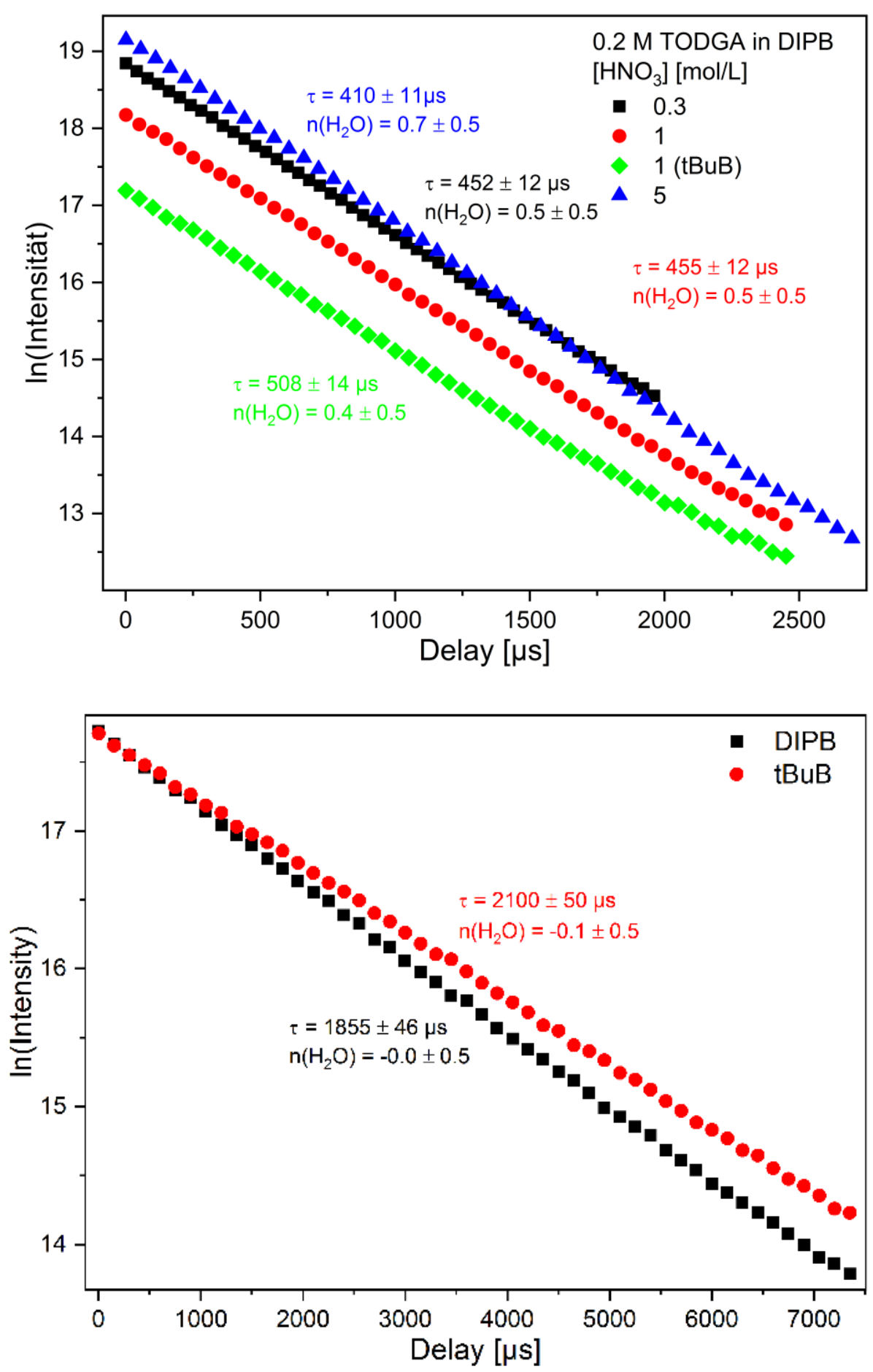

Fig. S3. Natural logarithm of the fluorescence intensity of the organic phase of extraction samples for the extraction of $\mathrm{Cm}$ (III) (top) or Eu(III) (bottom) with $0.2 \mathrm{~mol} / \mathrm{L}$ TODGA dissolved in DIPB or tBuB as a function of the delay time. $[\mathrm{Cm}(I I I)]_{\mathrm{ini}}=10^{-7} \mathrm{~mol} / \mathrm{L} ;[E u(I I I)]_{\mathrm{ini}}=10^{-5} \mathrm{~mol} / \mathrm{L}\left[H N O_{3}\right]_{\mathrm{ini}}=0.3-5 \mathrm{~mol} / \mathrm{L}$ (in case of $\mathrm{Eu}(\mathrm{III}): 1 \mathrm{~mol} / \mathrm{L}) ; A / O=1 ; t=30 \mathrm{~min} ; T=20^{\circ} \mathrm{C}$. 
Distribution ratios for the extraction of An(III) and Ln(III) with TODGA in DIPB and tBuB

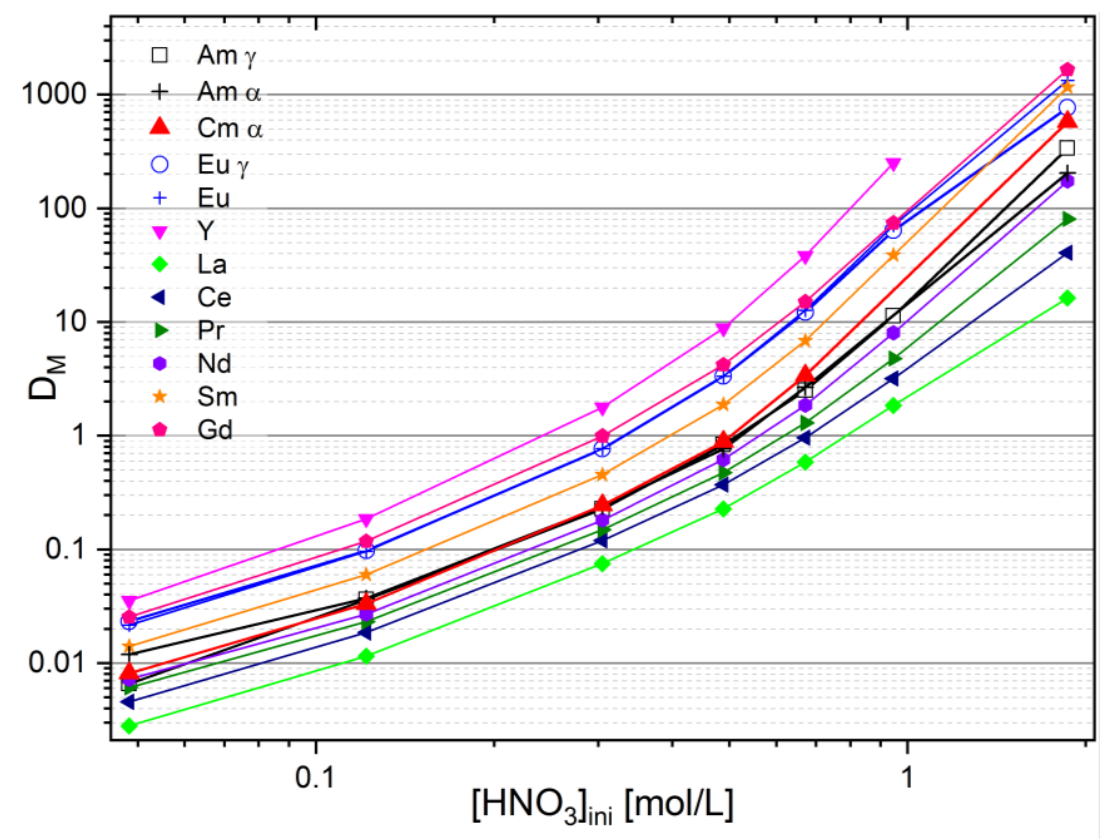

Fig. S4 A. Distribution ratios for the extraction of ${ }^{241} \mathrm{Am}(\mathrm{III}),{ }^{244} \mathrm{Cm}(\mathrm{III}),{ }^{154} \mathrm{Eu}(\mathrm{III}), \mathrm{Y}(\mathrm{III})$ and $\mathrm{La}(\mathrm{III})-$ $\mathrm{Gd}(\mathrm{III})$ with TODGA in $\mathrm{tBuB}$ as a function of the initial nitric acid concentration. [TODGA] $=0.2 \mathrm{~mol} / \mathrm{L}$; $A / O=1 ; t=30 \mathrm{~min} ; T=20^{\circ} \mathrm{C}$.

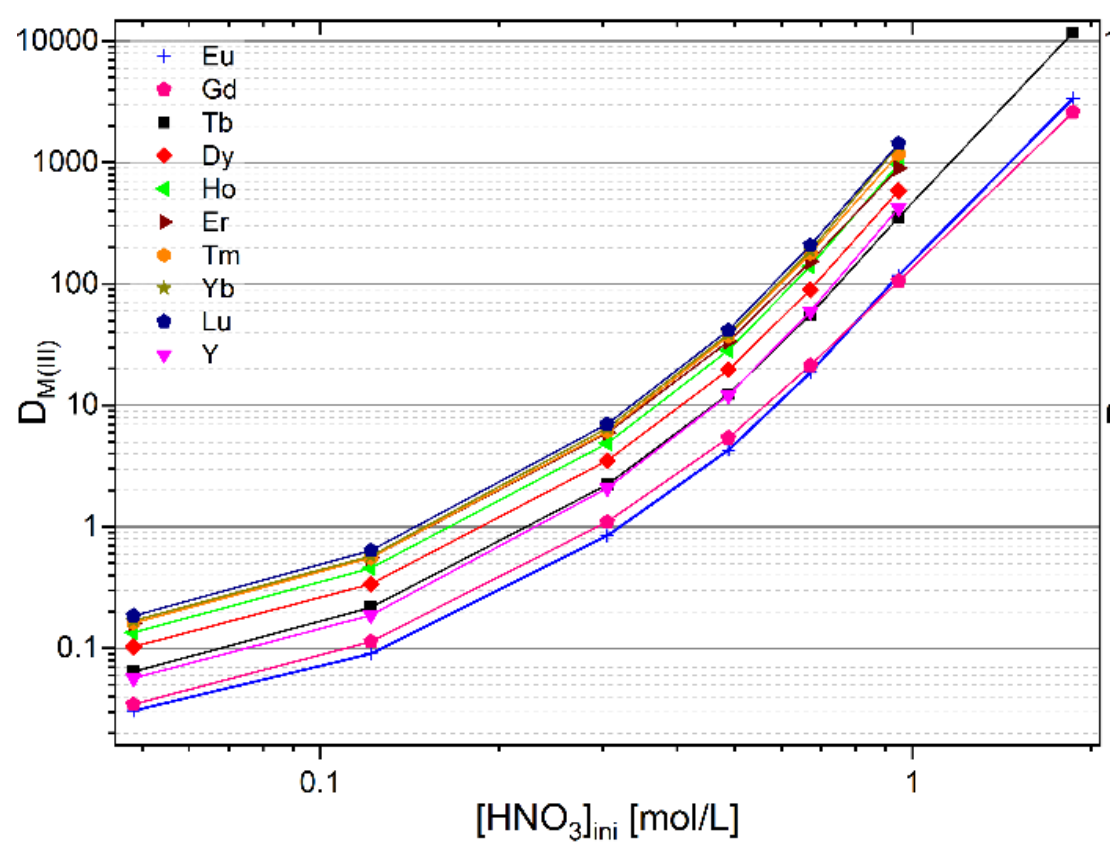

Fig. S4 B. Distribution ratios for the extraction of $\mathrm{Y}(\mathrm{III})$ and $\mathrm{Eu}(\mathrm{III})-\mathrm{Lu}(\mathrm{III})$ with TODGA in DIPB as a function of the initial nitric acid concentration. $[T O D G A]=0.2 \mathrm{~mol} / \mathrm{L} ; A / O=1 ; t=30 \mathrm{~min} ; T=20^{\circ} \mathrm{C}$. 


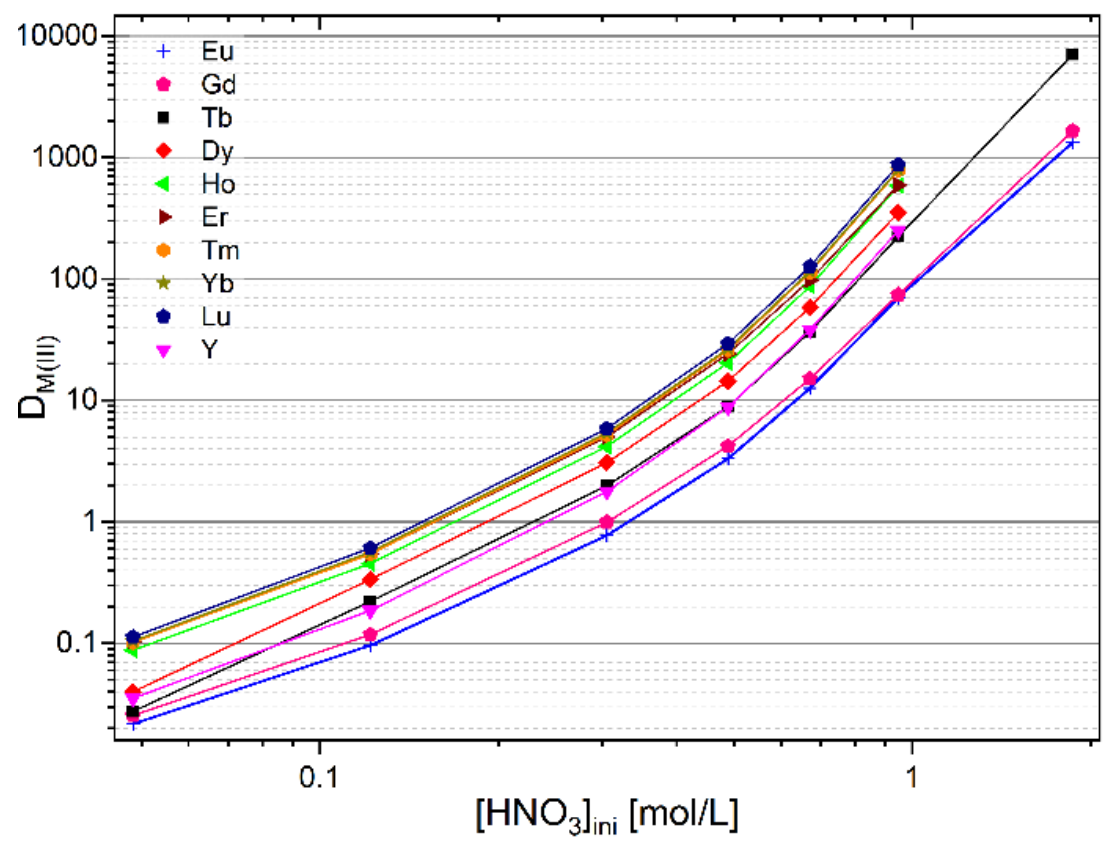

Fig. S4 C. Distribution ratios for the extraction of $\mathrm{Y}(\mathrm{III})$ and $\mathrm{Eu}(\mathrm{III})-\mathrm{Lu}(\mathrm{III})$ with TODGA in $\mathrm{tBuB}$ as a function of the initial nitric acid concentration. $[T O D G A]=0.2 \mathrm{~mol} / \mathrm{L} ; A / O=1 ; t=30 \mathrm{~min} ; T=20^{\circ} \mathrm{C}$.

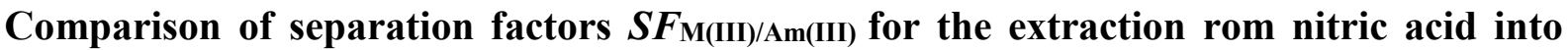
TODGA dissolved in aliphatic and aromatic diluents

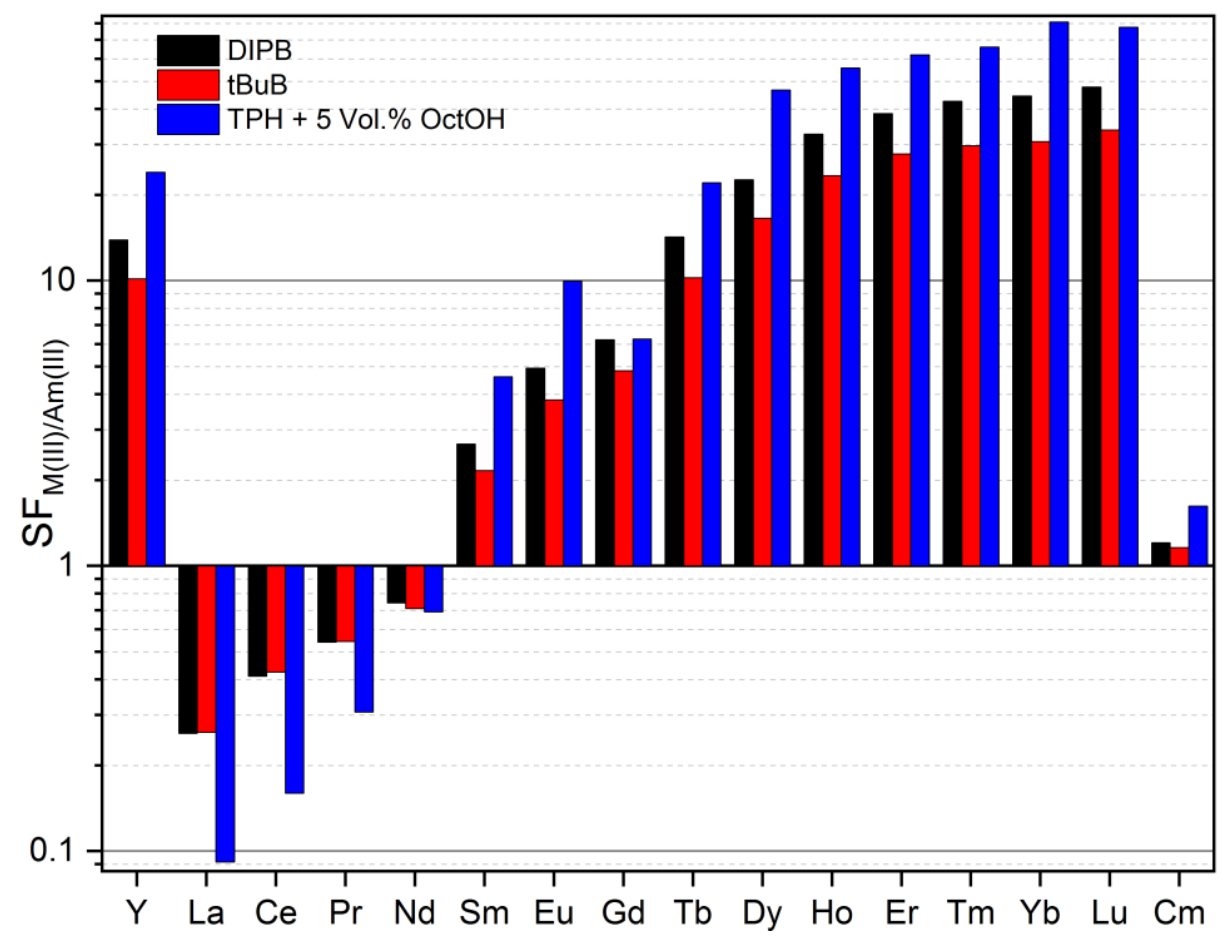

Fig. S5. Comparison of the $S F_{\mathrm{M}(\mathrm{III} / \mathrm{Am}(\mathrm{III})}$ values for $\mathrm{Y}(\mathrm{III}), \mathrm{Ln}(\mathrm{III})$ and $\mathrm{Cm}(\mathrm{III})$ for the extraction from $0.5 \mathrm{~mol} / \mathrm{L} \mathrm{HNO}_{3}$ into $0.2 \mathrm{~mol} / \mathrm{L}$ TODGA dissolved in aromatic diluents (DIPB, tBuB) and an aliphatic diluent (TPH with 5 vol.\% 1-octanol; data from reference ${ }^{1}$ ). 
Distribution ratios for the heavy lanthanides for the extraction with TODGA in DIPB at different temperatures.

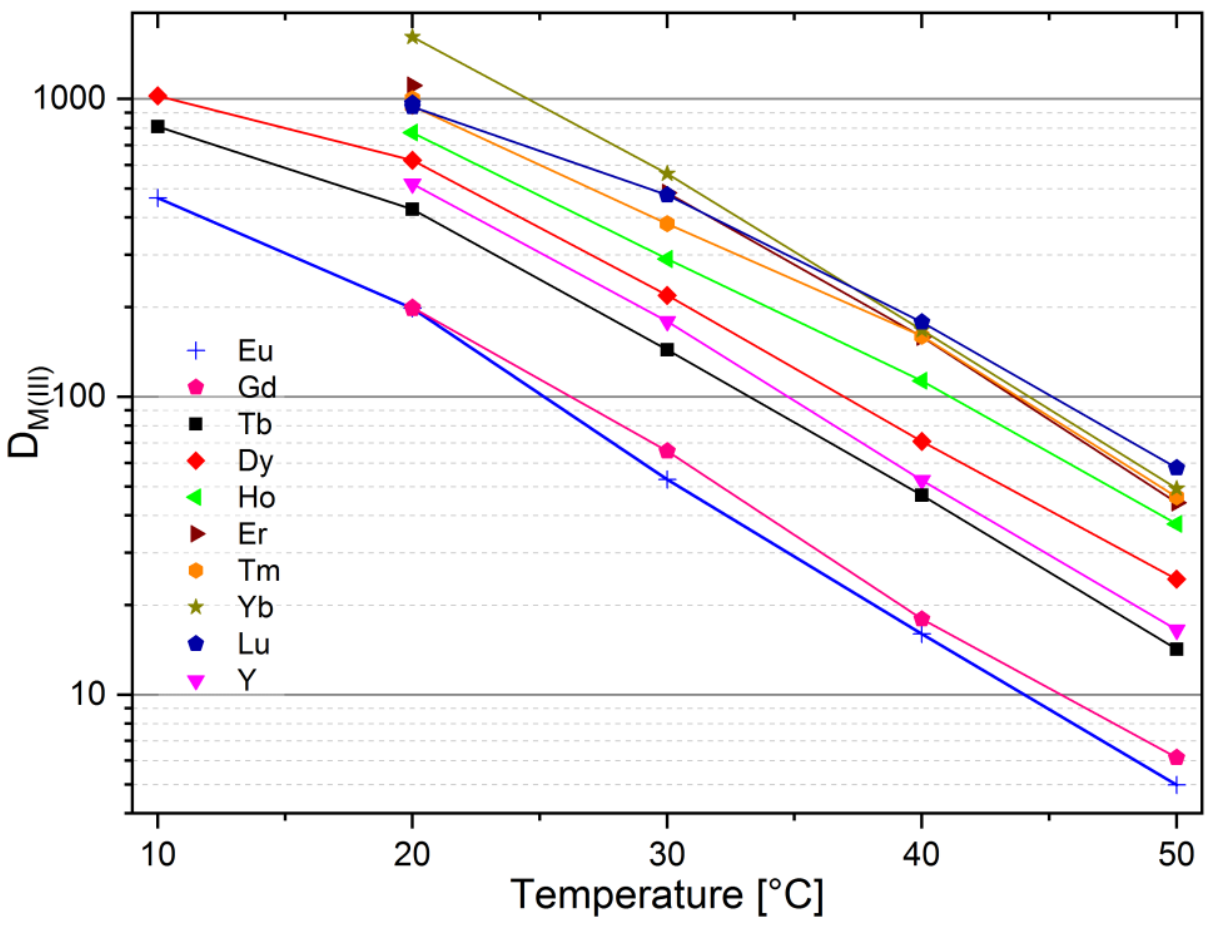

Fig. S6. Distribution ratios of $\mathrm{Y}(\mathrm{III})$ and $\mathrm{Eu}(\mathrm{III})-\mathrm{Lu}(\mathrm{III})$ for the extraction with TODGA in DIPB as a function of the temperature. $\left[\mathrm{HNO}_{3}\right]=1 \mathrm{~mol} / \mathrm{L} ;[T O D G A]=0.2 \mathrm{~mol} / \mathrm{L} ; A / O=1 ; t=30 \mathrm{~min}$. 


\section{Normalized Eu(III) emission spectra from TODGA in DIBP or TPH + 5 vol.\% 1-octanol organic phases loaded with Ln(III)}
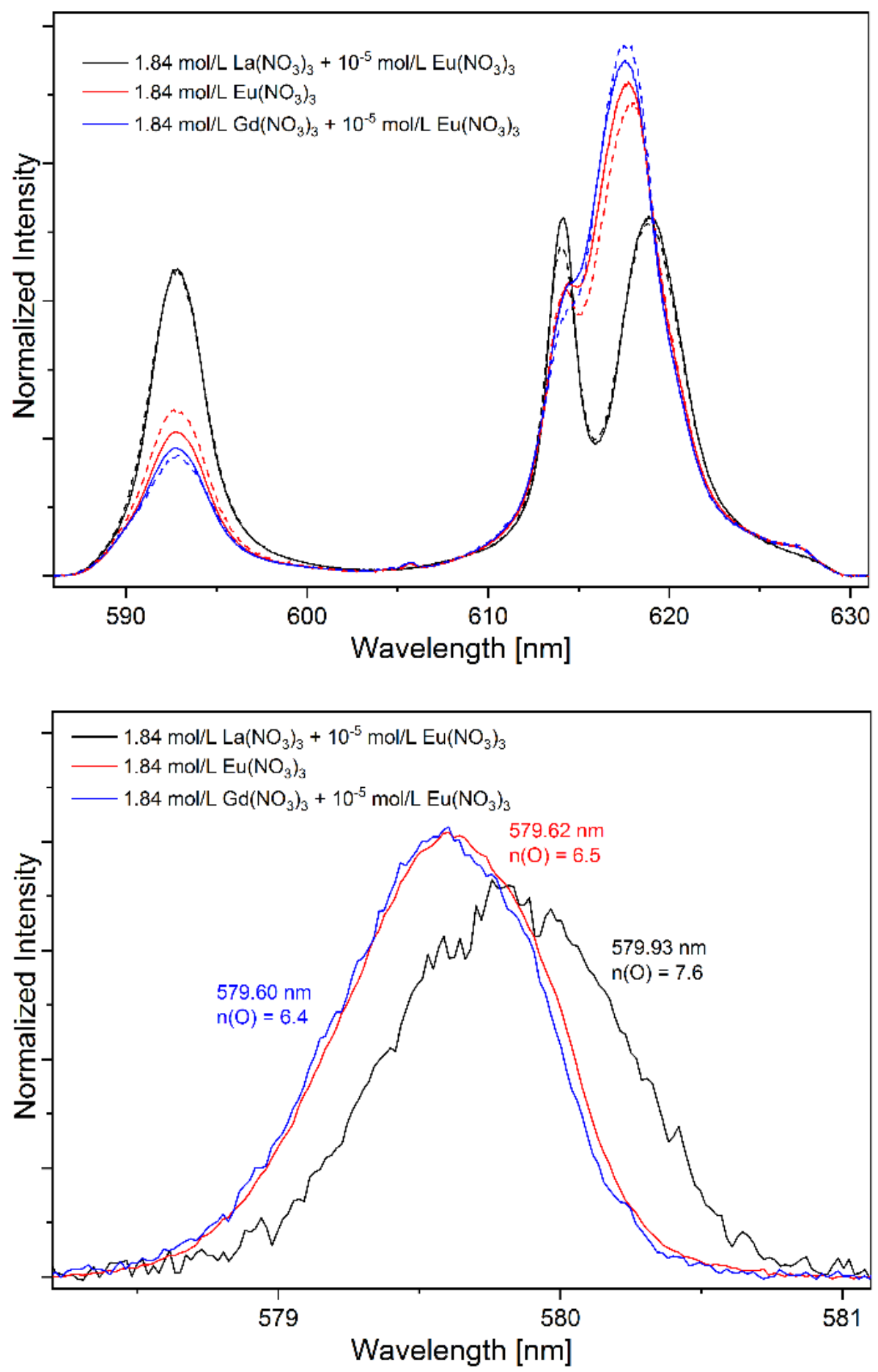

Fig. S7. Normalized $\mathrm{Eu}(\mathrm{III})$ fluorescence emission spectra from organic phases loaded with $\mathrm{Ln}(\mathrm{III})$. Top, ${ }^{5} \mathrm{D}_{0}$ $\rightarrow{ }^{7} \mathrm{~F}_{n}(n=1,2)$ transition; TODGA in DIPB (continuous lines) or TPH +5 vol.\% 1-octanol (dashed lines). Bottom, ${ }^{5} \mathrm{D}_{0} \rightarrow{ }^{7} \mathrm{~F}_{0}$ transition; TODGA in TPH +5 vol.\% 1-octanol.

Organic phases ( $0.1 \mathrm{~mol} / \mathrm{L}$ TODGA in DIPB or TPH +5 vol.\% 1-octanol) loaded with $\mathrm{Ln}(\mathrm{III})(\mathrm{Y}, \mathrm{La}, \mathrm{Nd}$, $\mathrm{Sm}, \mathrm{Eu}, \mathrm{Gd}, \mathrm{Er})$. Aqueous phases, initially $10^{-5} \mathrm{~mol} / \mathrm{L} \mathrm{Eu}\left(\mathrm{NO}_{3}\right)_{3}$ and $1.84 \mathrm{~mol} / \mathrm{L} \mathrm{Ln}\left(\mathrm{NO}_{3}\right)_{3}$ in $1 \mathrm{~mol} / \mathrm{L} \mathrm{HNO}_{3}$. $A / O=1, t=30 \mathrm{~min}, T=20^{\circ} \mathrm{C}$. 
Decay of the Eu(III) fluorescence intensity from TODGA in TPH + 5 vol.\% 1-octanol organic phases loaded with $\operatorname{Ln}($ III)

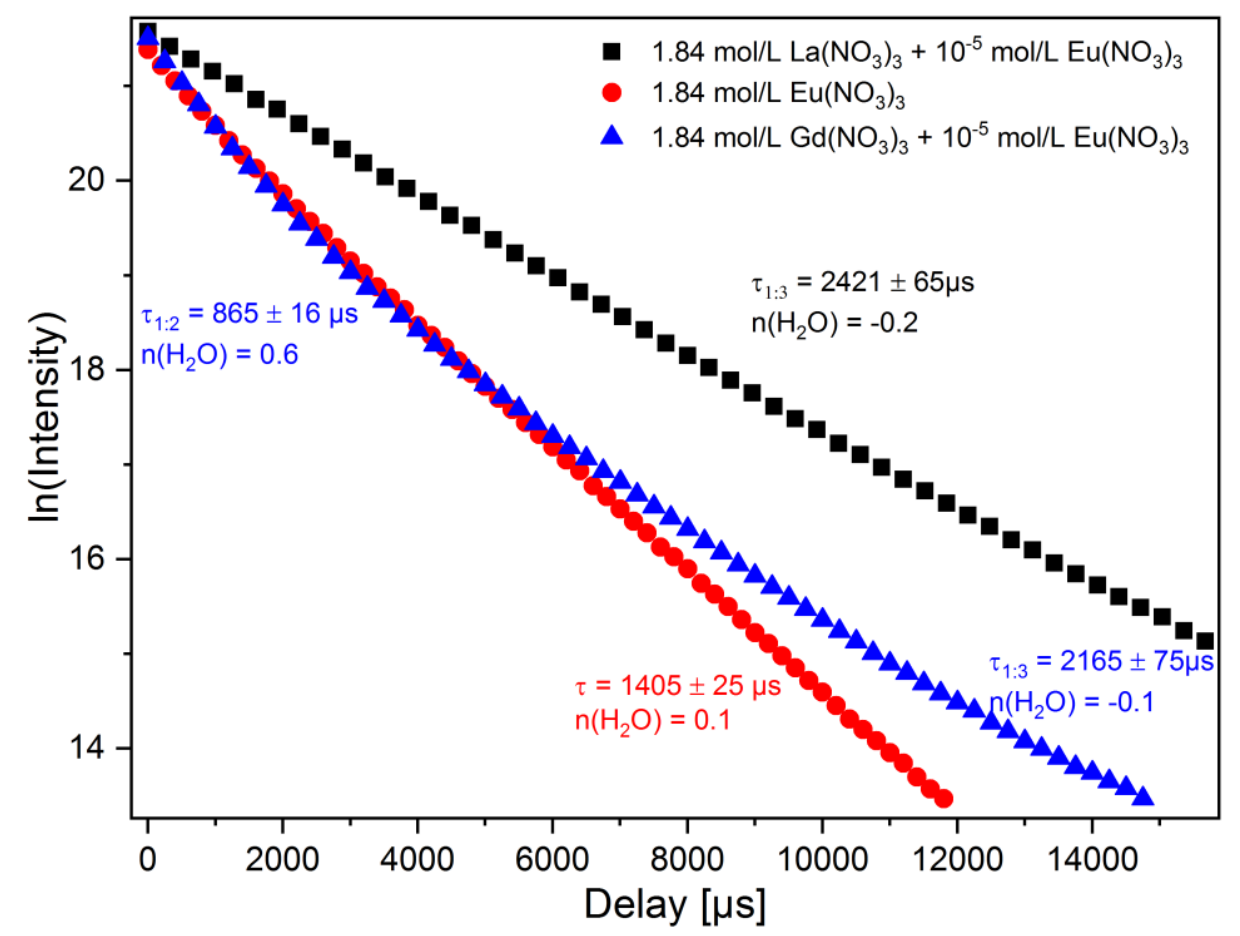

Fig. S8. Natural logarithm of the fluorescence intensity from organic phases loaded with $\operatorname{Ln}(\mathrm{III})$ as a function of the delay time. Experimental conditions, see Fig. S7; diluent was TPH +5 vol\% 1-octanol.

\section{References}

1. Geist, A.; Müllich, U.; Magnusson, D.; Kaden, P.; Modolo, G.; Wilden, A.; Zevaco, T., Actinide(III)/Lanthanide(III) Separation Via Selective Aqueous Complexation of Actinides(III) using a Hydrophilic 2,6-Bis(1,2,4-Triazin-3-Y1)-Pyridine in Nitric Acid. Solvent Extr Ion Exc 2012, 30 (5), 433-444. 